\title{
Borrelia burgdorferi infection modifies protein content in saliva of Ixodes scapularis nymphs
}

Tae Kwon Kim², ${ }^{1,2}$ Lucas Tirloni ${ }^{1,3}$, Emily Bencosme-Cuevas' ${ }^{1}$, Tae Heung Kim¹', Jolene K. Diedrich ${ }^{4,5}$, John R. Yates $\|^{4}$ and Albert Mulenga ${ }^{1 *}$

\begin{abstract}
Background: Lyme disease (LD) caused by Borrelia burgdorferi is the most prevalent tick-borne disease. There is evidence that vaccines based on tick proteins that promote tick transmission of B. burgdorferi could prevent LD. As Ixodes scapularis nymph tick bites are responsible for most LD cases, this study sought to identify nymph tick saliva proteins associated with B. burgdorferi transmission using LC-MS/MS. Tick saliva was collected using a non-invasive method of stimulating ticks (uninfected and infected: unfed, and every $12 \mathrm{~h}$ during feeding through $72 \mathrm{~h}$, and fullyfed) to salivate into $2 \%$ pilocarpine-PBS for protein identification using LC-MS/MS.

Results: We identified a combined 747 tick saliva proteins of uninfected and B. burgdorferi infected ticks that were classified into 25 functional categories: housekeeping-like (48\%), unknown function (18\%), protease inhibitors (9\%), immune-related (6\%), proteases (8\%), extracellular matrix (7\%), and small categories that account for $<5 \%$ each. Notably, B. burgdorferi infected ticks secreted high number of saliva proteins $(n=645)$ than uninfected ticks $(n=376)$. Counter-intuitively, antimicrobial peptides, which function to block bacterial infection at tick feeding site were suppressed 23-85 folds in B. burgdorferi infected ticks. Similar to glycolysis enzymes being enhanced in mammalian cells exposed to $B$. burgdorferi : eight of the 10-glycolysis pathway enzymes were secreted at high abundance by $B$. burgdorferi infected ticks. Of significance, rabbits exposed to $B$. burgdorferi infected ticks acquired potent immunity that caused $40-60 \%$ mortality of B. burgdorferi infected ticks during the second infestation compared to $15-28 \%$ for the uninfected. This might be explained by ELISA data that show that high expression levels of immunogenic proteins in B. burgdorferi infected ticks.
\end{abstract}

Conclusion: Data here suggest that B. burgdorferi infection modified protein content in tick saliva to promote its survival at the tick feeding site. For instance, enzymes; copper/zinc superoxide dismutase that led to production of $\mathrm{H}_{2} \mathrm{O}_{2}$ that is toxic to $\mathrm{B}$. burgdorferi were suppressed, while, catalase and thioredoxin that neutralize $\mathrm{H}_{2} \mathrm{O}_{2}$, and pyruvate kinase which yields pyruvate that protects $\mathrm{Bb}$ from $\mathrm{H}_{2} \mathrm{O}_{2}$ killing were enhanced. We conclude data here is an important resource for discovery of effective antigens for a vaccine to prevent LD.

\footnotetext{
* Correspondence: amulenga@crm.tamu.edu

'Department of Veterinary Pathobiology, College of Veterinary Medicine, Texas A\&M University, College Station, Texas, United States of America

Full list of author information is available at the end of the article
}

(c) The Author(s). 2021 Open Access This article is licensed under a Creative Commons Attribution 4.0 International License, which permits use, sharing, adaptation, distribution and reproduction in any medium or format, as long as you give appropriate credit to the original author(s) and the source, provide a link to the Creative Commons licence, and indicate if changes were made. The images or other third party material in this article are included in the article's Creative Commons licence, unless indicated otherwise in a credit line to the material. If material is not included in the article's Creative Commons licence and your intended use is not permitted by statutory regulation or exceeds the permitted use, you will need to obtain permission directly from the copyright holder. To view a copy of this licence, visit http://creativecommons.org/licenses/by/4.0/ The Creative Commons Public Domain Dedication waiver (http://creativecommons.org/publicdomain/zero/1.0/) applies to the data made available in this article, unless otherwise stated in a credit line to the data. 


\section{Background}

Tick-borne diseases account for the largest share of human vector-borne diseases reported in the US and its territories. Between 2004 and 2016, nearly 650,000 cases of human vector-borne diseases were reported in the US and its territories, of which $75 \%(491,671)$ were tickborne. During this period, Lyme disease (LD) caused by Borrelia burgdorferi $(B b)$, accounted for 82\% (402,502/ $491,671)$ of the reported human TBD cases [1]. Currently, vaccines against major human tick-borne disease including LD are not available and the primary prevention efforts rely on avoidance of infectious tick bites through different methods which include personal protection equipment, reduction of infected tick populations by means of landscape management, and application of acaricides to kill vector ticks that infest wildlife blood meal sources [1-7]. Despite the availability of these tick control measures, annual LD cases of nearly 30,000 are reported to the US Centers for Disease Control, with actual cases estimated to exceed 300,000 annually [1]. This has justified the need to develop alternative LD prevention methods, and tick-antigen based vaccines have emerged as the most promising [8-10]. The feasibility of using vaccines to control tick infestation was validated with the commercialization the vaccine against cattle fever ticks, Rhipicephalus (Boophilus) microplus that was based on a Bm86 tick midgut antigen [11]. The major limitation has been the lack of effective target antigens to control geographically distinct and other tick species.

There is evidence that tick saliva proteins facilitate transmission of B. burgdorferi and other tick-borne disease agents [12]. Importantly the concept of tick-antigen based vaccines as a strategy to prevent LD and other tick-borne disease infections is based on findings that the repeated inoculation of tick saliva proteins into repeatedly infested animals provoked significant anti-tick immunity that resulted in ticks failing to feed and transmitting B. burgdorferi [13, 14]. These findings have resulted in a renewed interest in targeting tick saliva proteins in vaccines to prevent LD and other tick-borne disease infections $[9,10,15]$. The approach toward developing tick salivary antigen-based vaccines to prevent tick-borne disease infections has been to understand the molecular basis of tick feeding physiology as a means through which, we can discover effective tick saliva proteins for tick-antigen based vaccines. The starting point of this research is the discovery and characterization of proteins in saliva of ticks that regulate tick feeding and facilitate in the transmission of tick-borne disease agents, which has been attempted through transcriptomics [16-18], immuno-proteomics [19, 20], and tick saliva proteomics [21-26]. There is evidence that tickborne disease infections of ticks modified transcription and protein expression patterns in different tick species
[27-31]. Prompted by these findings, the objective of this study was to identify proteins in saliva of $B$. burgdorferi-infected $I$. scapularis nymphs every $12 \mathrm{~h}$ of feeding. Although adult ticks are capable of transmitting B. burgdorferi, we focused on nymphs since majority of human LD infections reported was associated with infectious nymph tick bites [32-34].

Here we used LC-MS/MS to identify and bioinformatically characterize 747 proteins in saliva of uninfected and $B$. burgdorferi-infected $I$. scapularis nymphs at different stages of the tick feeding process: unfed, those that partially-fed on rabbits for $12,24,36,48,60$, and 72 $\mathrm{h}$, and replete fed. Our data show that B. burgdorferi infection modified the protein content in saliva of infected I. scapularis nymph ticks. The approach described here has allowed us to identify I. scapularis nymph tick saliva proteins that are suppressed, induced, enhanced, or not affected in response to B. burgdorferi infection of $I$. scapularis nymphs. Of particular significance, saliva of $B$. burgdorferi infected ticks contained higher number of proteins than the uninfected. We speculate that this could explain our observation that a single infestation of rabbits by $B$. burgdorferi infected ticks provoked strong anti-tick immunity that resulted in $40-60 \%$ mortality of $B$. burgdorferi infected ticks during the second infestation compared to $20 \%$ on uninfected rabbits. We discuss our data with reference to understanding the molecular basis of tick transmission of the LD agent.

\section{Results}

\section{Exposing Ixodes scapularis nymph tick mouthparts to} pilocarpine induces salivation

Borrelia burgdorferi infected I. scapularis nymphs that were used in this study were successfully infected by artificially feeding [35] and summarized in supplemental figure (SF) 1. Our rationale to artificially infect ticks was to ensure $100 \%$ B. burgdorferi infection in all ticks that were used for saliva collection. We confirmed that $B$. burgdorferi infected nymph ticks were able to transmit $B$. burgdorferi to rabbits by ELISA and western blotting analyses of cultured $B$. burgdorferi protein extracts using purified IgG of rabbits that were infested by uninfected and B. burgdorferi infected ticks (SF2A and SF2B).

Prior to this study, collection of tick saliva required injecting ticks with pilocarpine or applying pilocarpineethanol solution on the dorsal side of the tick to stimulate salivation and then collect saliva into capillary tubes that were affixed onto tick mouthparts [36]. Given the smaller size of $I$. scapularis nymphs injecting pilocarpine was problematic, as majority of nymphs could not survive the injection trauma. In this study, we have validated a non-invasive approach to collect tick saliva by allowing nymph ticks to salivate directly into pipette tips that contained 2\% pilocarpine in PBS pH 7.4 (as shown 
in SF1). We successfully collected sufficient amount of nymph tick saliva by inserting I. scapularis nymph tick mouthparts into $10 \mu \mathrm{L}$ pipette tips that contained $2 \%$ pilocarpine solution $(5 \mu \mathrm{L})$. This allowed ticks to salivate directly into pilocarpine and prevented saliva from drying out. We successfully collected $\sim 13,9,20,18,37,27$, 43 , and $20 \mu \mathrm{g}$ total saliva proteins from unfed $(n=50)$, partially-fed on rabbits for $12,24,36,48,60$, and $72 \mathrm{~h}$ ( $n=30$ per time point) and replete-fed $(n=15)$ B. burgdorferi infected ticks. Likewise, we collected 11, 18, 18, 13, $21,11,15$, and $9 \mu \mathrm{g}$ of uninfected tick saliva proteins respectively. To validate and visualize protein profiles in collected saliva, $\sim 1.5 \mu \mathrm{g}$ of total tick saliva proteins per time point were resolved on SDS-PAGE and analyzed by silver staining (SF3).

\section{Borrelia burgdorferi-infected Ixodes scapularis nymphs secrete more proteins than the uninfected}

To identify proteins in tick saliva, $2 \mu \mathrm{g}$ of total tick saliva protein per run (in triplicate) was analyzed by LC-MS/ MS as described [21-26]. A notable finding in this study is that B. burgdorferi infected ticks secreted high number of saliva proteins $(n=645)$ compared to the uninfected ticks $(n=376)$. Overall, we identified a combined 747 tick proteins in saliva of uninfected and B. burgdorferi-infected I. scapu4laris nymphs that were classified in 25 functional categories (Supplemental Table (ST) 1 and 2). Except for replete fed (96-120 h fed) B. burgdorferi infected ticks that secreted fewer proteins compared to uninfected (2.2 folds lower), all other B. burgdorferi infected feeding stages secreted more proteins than uninfected by factors of 4.3 folds in unfed ticks and 1.7, 2.2, 1.9,1.5, 2.1 and 2.6 folds in 12, 24, 36, 48, 60, and $72 \mathrm{~h}$ fed ticks respectively (Fig. . 1 and ST2).

Antimicrobial peptides (AMP) in tick saliva are expected to suppress bacteria growth at the tick feeding site and clear microbes in blood meal [37]. Therefore, it is noteworthy that B. burgdorferi infection completely blocked secretion of 4 of the 5 AMPs that were identified in uninfected ticks (ST1). In contrast, two functional categories: amino acid metabolism and transcription machinery proteins were only detectable in saliva of $B$. burgdorferi infected ticks (ST2); suggesting that secretion of these proteins into tick saliva was induced by $B$. burgdorferi infection. With exception of three functional categories (nuclear regulation, glycine rich, and mucin) for which both uninfected and $B$. burgdorferi infected ticks secreted the same number of proteins, $B$. burgdorferi infection caused ticks to secrete more proteins for the remaining functional categories. B. burgdorferi infection caused ticks to secrete more proteins by factors of between 2.0-16 folds in functional categories of metabolism proteins (carbohydrates, nucleic acids, energy and lipids), immune related, proteases, transporters/ receptors, signal transduction, protein export, and proteasome machinery. Likewise, saliva of $B$. burgdorferi infected ticks contained more proteins by factors between 1.1-1.9 folds for protease inhibitors, tick-specific proteins of

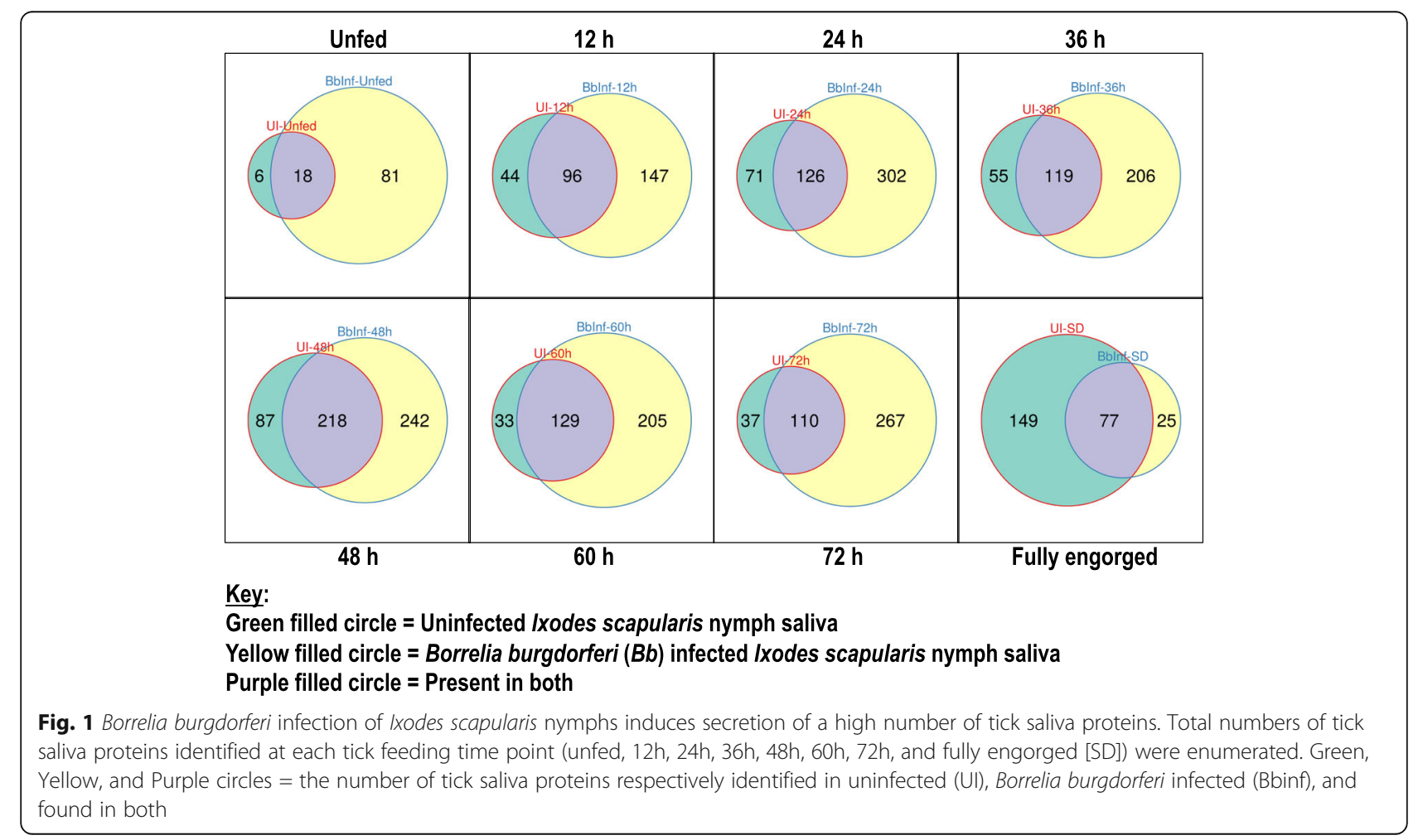


unknown function, detoxification/antioxidant, cytoskeletal, extracellular matrix, protein modification, heme/ iron binding, protein synthesis, and histamine-binding proteins/ lipocalins (ST2).

\section{Borrelia burgdorferi infection modifies secretion dynamics} of Ixodes scapularis nymphs tick saliva proteins

To gain further insight into temporal secretion dynamics of proteins at different tick feeding timepoints, the sum total of the normalized spectral abundance factor (NSAF), an index for relative protein abundance [38-41] for each functional category was used to generate the heatmap using R package [41] (Fig. 2; NSAF values used to generate heatmaps shown in ST2). The heatmap reveals seven secretion pattern trends: branches A-G. Overall the sum total relative abundance of tick saliva proteins in branch A (signal transduction, antimicrobial, TSP of unknown function, and protein synthesis), branch B (cytoskeletal, extracellular matrix, and glycine rich), nuclear regulation in branch $E$, lipocalin in branch $F$ were suppressed in saliva of $B$. burgdorferi infected ticks. Likewise, functional categories in branch B (cytoskeletal, extracellular matrix, and glycine rich) and branch $E$ (protease and protease inhibitors) were suppressed in response to $B$. burgdorferi infection. In contrast, tick saliva proteins in 14 functional categories were secreted at high abundance by $B$. burgdorferi infected ticks. These include transcriptional machinery, heme/ion binding, mucin, and lipid metabolism in branch $\mathrm{C}$; immune related, energy metabolism, transporters/receptors, detoxification/antioxidant, amino acid metabolism, and carbohydrate metabolism in branch $\mathrm{D}$; and proteasome machinery, nucleic acid metabolism, protein modification, and protein export in branch G. Finally, proteases and protease inhibitors in branch $\mathrm{E}$ were secreted by both uninfected and infected ticks at comparable levels. Overall, data in Fig. 2 provides insights into functional categories that might be associated with transmission of $B$. burgdorferi as these were secreted at high abundance by $B$. burgdorferi infected ticks.

\section{Borrelia burgdorferi infection modifies relative abundance of Ixodes scapularis nymph tick saliva proteins}

To gain further insight on the effects of B. burgdorferi infection on relative abundance tick saliva protein functional categories, sum totals of NSAF values for each

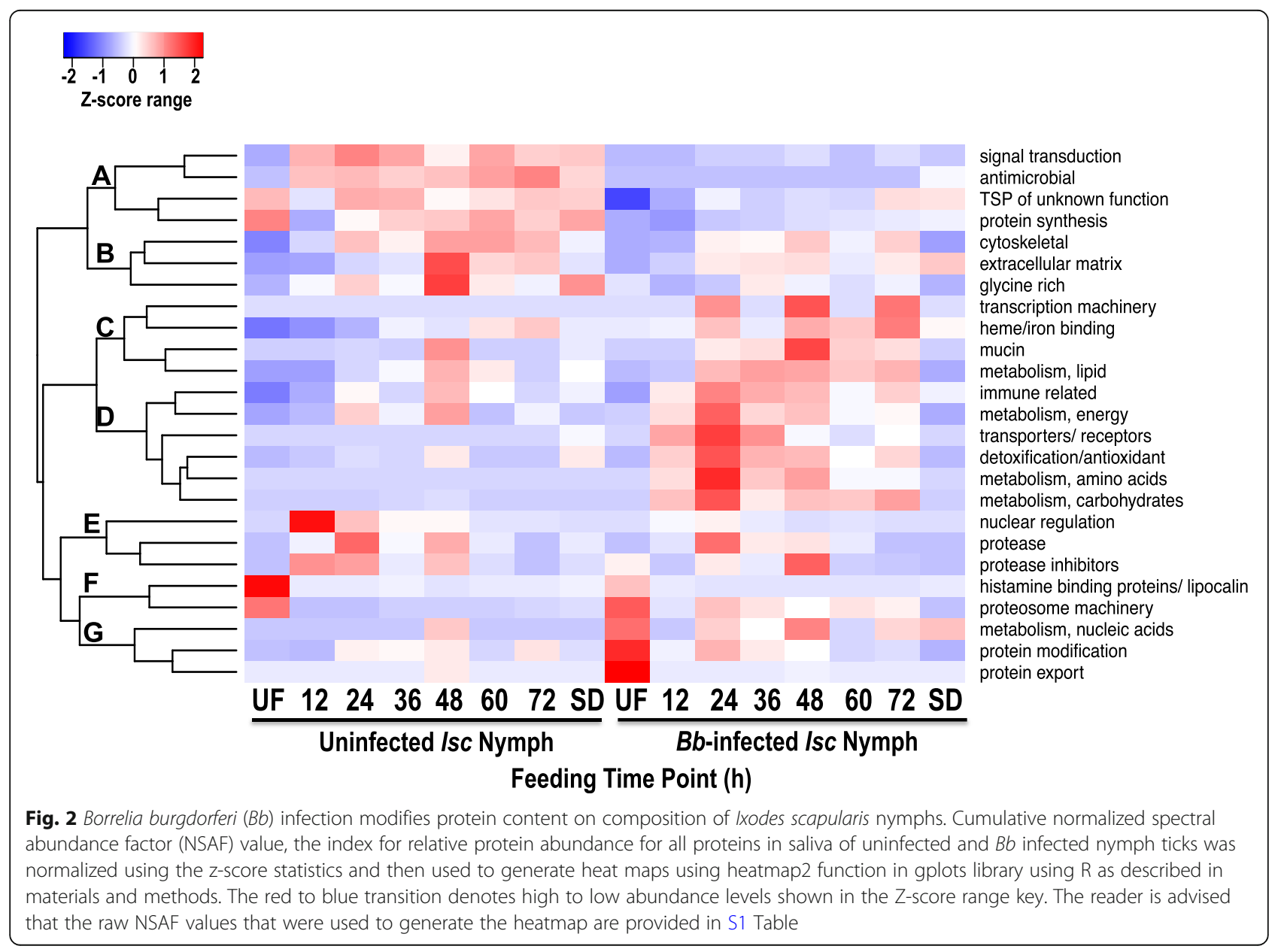




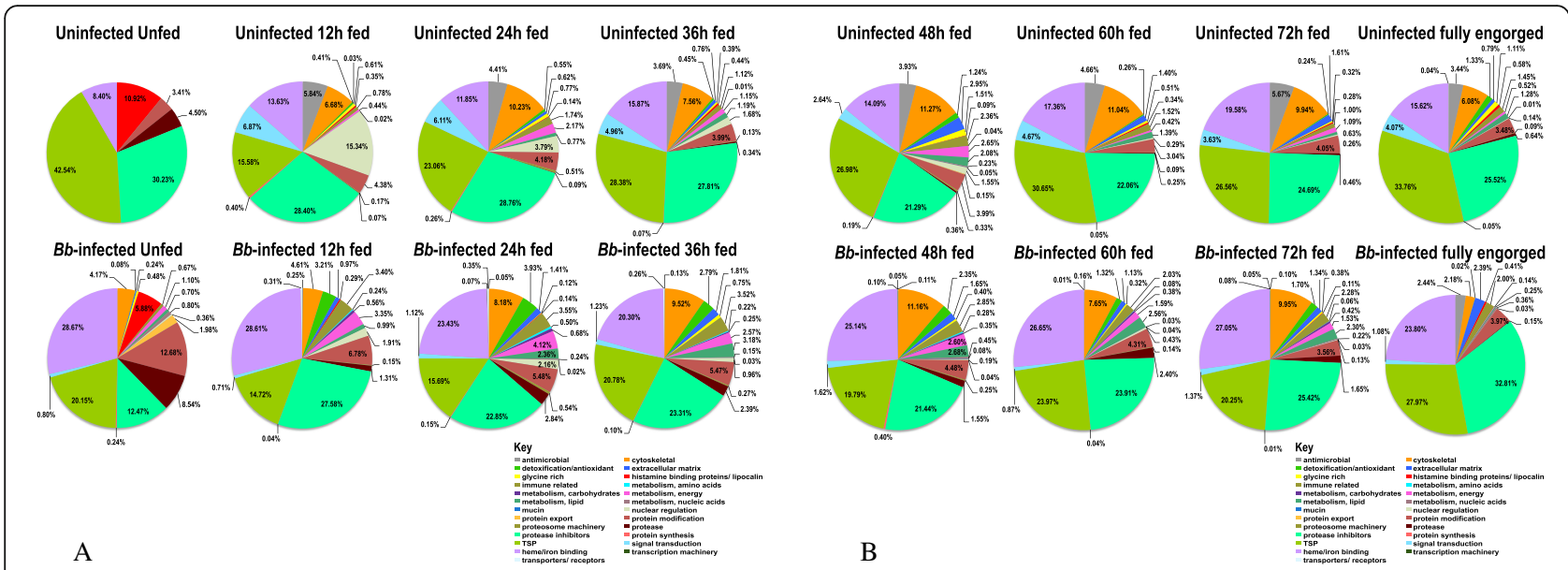

Fig. 3 Temporal relative abundance of proteins in saliva of uninfected and Borrelia burgdorferi (Bb) infected Ixodes scapularis nymphs. Relative abundance (based on average normalized spectral abundance factors) for each functional category is expressed as a percent (\%) of total protein content of unfed and 12, 24, and $36 \mathrm{~h}$ fed ticks (a) and 48,60,72h, and replete fed ticks (b). Please read the key from left to right and the pie chart in a clockwise direction, starting from the antimicrobial peptides (grey color). Please note that antimicrobial peptides are absent in unfed ticks, and are less than $1 \%$ in $B b$ infected ticks

functional category, the index for relative protein abundance [38-41] were expressed as percent of relative total protein content per time point (Fig. 3). The most abundant categories in both uninfected and $B$. burgdorferi-infected ticks belong to protease inhibitors (chartreuse green), TSPs (green), heme/iron binding proteins (purple), cytoskeletal (orange), proteases (brown), and antimicrobial (gray); with the rest of categories accounting for less than $4 \%$ each. Fold changes in relative protein abundance between uninfected and B. burgdorferi infected ticks are summarized in ST2. The most notable effects of $B$. burgdorferi infection is on relative abundance of AMPs (gray) in tick saliva, which was suppressed by 23-85 folds: reducing from 3-6\% of total proteins in uninfected tick saliva to less than $1 \%$ in B. burgdorferi infected ticks during the 12-72 $\mathrm{h}$ feeding period, but not in replete fed (96-120 h fed) ticks where relative abundance is apparently similar. As shown in ST2, the other functional categories that were suppressed in response to $B$. burgdorferi infection include lipocalin (1.2-2.5 folds), TSP of unknown function (1.2-2.1 folds), signal transduction (1.6-9.6 folds), nuclear regulation (1.7-8.0 folds), and glycine rich proteins (0.6-6.6 folds). The effects of B. burgdorferi infection on protease inhibitors was mixed in that, relative abundance was reduced by 1-2.4 folds in unfed and 12-36 h fed ticks: however relative abundance was increased by up to 1.28 folds in $48-72 \mathrm{~h}$ fed and replete fed (96-120 h fed) ticks. Similarly, the protein synthesis functional category was suppressed by up to 1.211 folds for 12, 24, and $60 \mathrm{~h}$ fed ticks, but enhanced by $0.8-2.4$ folds in unfed and 36, 48, and $72 \mathrm{~h}$ fed ticks. The same pattern was observed for cytoskeletal proteins; suppressed by 1-2.8 folds in 12, 24, 48, $60 \mathrm{~h}$ fed and replete fed (96-120 h fed), but enhanced by 1-4.2 folds in unfed, 36 and $72 \mathrm{~h}$ fed ticks.

\section{Secretion dynamics profiling reveals proteins likely associated with transmission of Borrelia burgdorferi}

The heatmap in SF4 highlights the overall secretion dynamics of all 747 tick saliva proteins based on NSAF values (present in at least 2 of the 3 runs per time point, raw values in ST1) as index for relative abundance. Similar to observations in Fig. 2, the heatmap for all proteins in SF4 reveals that B. burgdorferi infection had three broad effects: suppression, enhancement or unmodified (no effect) on tick saliva secretion.

To gain insight on effects of B. burgdorferi infection on individual proteins in this study, a selected group of functional categories (protease inhibitors, proteases, lipid metabolism-associated proteins, antimicrobial peptides, and histamine binding proteins/ lipocalins) were graphed in PRISM8 (Graphpad Software Inc., San Diego CA, USA) (Figs. 4a-f). Secretion dynamics of the remaining functional categories are presented as heatmaps in SF5. Tick housekeeping protein-like functional categories have been discussed as a group, with commentary on key highlights. We have also commented on the effect of B. burgdorferi infection on secretion of rabbit proteins in tick saliva. To provide context, we have commented on probable functional roles of tick saliva proteins tick transmission of $B$. burgdorferi. 


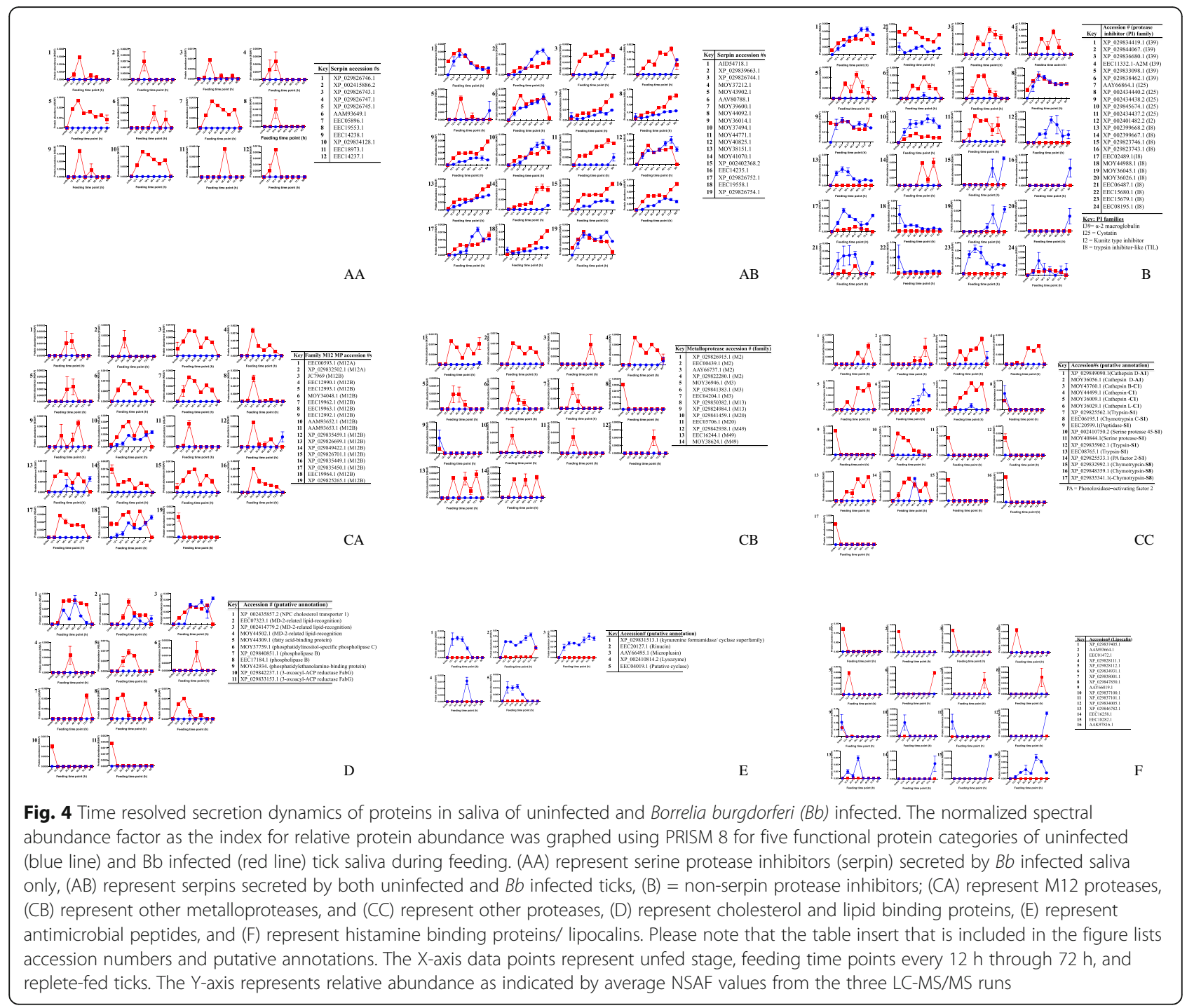

\section{Protease inhibitors (PI)}

We previously showed that ticks encoded at least 18 of the 79 protease inhibitors (PI) families that are listed in the MEROPS database [42-44]. In this study, we identified 71 PIs in five PI families: Kunitz type (I2, n=1), serine protease inhibitors (serpin, family $I 4, n=34$ ), trypsin inhibitor-like (TIL, family I8, $\mathrm{n}=17$ ), cystatin (family I25, $\mathrm{n}=10$ ), and $\alpha-2$ macroglobulin (family I39, A2M, $\mathrm{n}=$ 9) (Figs. 4AA, 4AB, and 4B: Due to high of PIs, we have split Fig. 4A into $4 \mathrm{AA}$ and $4 \mathrm{AB}$ [serpins] and 4B [nonserpin protease inhibitors]). Similar to protein content in saliva of adult ticks $[22,24,26]$, data here show that majority of the PIs in saliva of both uninfected and $B b$ infected nymphs were serine protease inhibitors (serpins). Although serpins are the majority PIs in tick saliva, they are second behind family I2 (Kunitz serine PI) among tick-encoded PIs [43]. Interestingly, we found a single family I2 PIs in nymph saliva, and they accounted for only 2 of the 43 PIs that were identified in saliva of adult I. scapularis [24]. These findings might suggest a limited role for Kunitz-type serine protease inhibitors in regulating feeding and transmission of B. burgdorferi by ticks.

Serpins The tick feeding style of disrupting host tissue and then imbibing the host blood that bleeds into the wounded lesion is expected to trigger host defense pathways that initiate wound healing and prevent further blood loss. The host defense pathways triggered by tick feeding such as hemostasis, complement, and inflammation pathways are mediated by serine proteases that are under tight regulation by serpins [45-48]. From this perspective, it has been hypothesized that ticks might utilize serpins to evade host defense [49-51]. On this basis it is notable that 34 of the 71 PIs found in this study are serpins. Due to the high number of serpins, we have split them into those identified in saliva of $B$. burgdorferi 
infected ticks only (Fig. 4AA, $n=13$ ) and those identified in saliva of both uninfected and B. burgdorferi infected ticks (Fig. 4AB, $n=21$ ). We would like the reader to note here and elsewhere that representative graphs are shown for serpins (and other proteins) that display similar secretion patterns. Serpins showing similar secretion patterns include Fig. 4AA (4XP_029826747.1 and EEC19554.1), Fig. 4AB2 (XP_029839663.1 and EEC08061.1), and Fig. 4AB8 (MOY44092.1 and XP_ 029826753.1). It is notable that the relative abundance for majority of serpins that were secreted by $B$. burgdorferi infected tick only was highest at 24-48 h tick feeding time points (Fig. 4AA) preceding the major transmission events of B. burgdorferi after the tick has fed for more than $48 \mathrm{~h}$ [32-34]. It is also notable that 12 of the 21 serpins that were secreted by both uninfected and $B$. burgdorferi infected ticks were enhanced in B. burgdorferi response to infection (Fig. 4AB) suggesting the possibility that they are associated with transmission of $B$. burgdorferi.

Some of the serpins in this study were previously characterized including AID54718.1 (Fig. 4AB1) as an inhibitor of thrombin, blood clotting and platelet aggregation [52]. Similarly, EEC18973.1 (Fig. 4AA11), is one of the highest conserved tick serpins known to date; its functional reactive center loop is $100 \%$ conserved in tick species where data was available [52, 53]. Importantly, RNAi silencing of EEC18973.1 [54] or its homolog in A. americanum (AAS19) [55] caused deformities in ticks, reduced blood meal sizes, and tick mortalities. Indirect evidence based on functional analysis of AAS19 suggests that EEC18973.1 is likely a glycosaminoglycan-binding serpin and an inhibitor of platelet aggregation and blood clotting $[53,56]$. It is also notable that, XP_002402368.2 (Fig. 4AB15) is a homolog to I. ricinus ABI94056.2, an anti-inflammatory protein that acts by inhibiting chymase and cathepsin G [57]. Taken together, the abundance of these serpins in B. burgdorferi infected ticks at early stages of feeding could be important in responding to early host defense such as hemostasis and inflammation for successful transmission and dissemination of $B$. burgdorferi into the mammalian host.

Non-serpin protease inhibitors The 37 non-serpin PIs include alpha-2 macroglobulin ( $n=9$; A2M, Fig. 4B1-6, note that four A2M, XP_029834419.1, XP_029834431.1, XP_029834426.1, and MOY43687 are represented by Fig. 4B1), ten cysteine protease inhibitors (cystatins, Fig. 4B7-11, AAY66864.1 and MOY41952.1, XP_ 002434440.2 and Q8MVB6.1, XP 029845674.1, B7PKZ1.1 and 3MWZ.1 are respectively represented by Fig. 4B7, Fig. 4B8; and Fig. 4B10). The other non-serpin PIs include a single Kunitz type inhibitor (Fig. 4B12), and 17 trypsin inhibitor-like inhibitors (TIL, Fig. 4B13-
24) with XP_002399668.2 and XP_029825278.1; XP 029823746.1 and MOY36044.1; XP_029823743.1, MOY43102.1 and MOY43175.1; and .1 and $\mathrm{XP}_{-}$ 029823423.1 are respectively represented in Fig. 4B13, Fig. 4B15, Fig. 4B16, and Fig. 4B17).

Except for the A2M in Fig. 4B1 that was not affected by $B$. burgdorferi infection, the rest of A2Ms were secreted at high abundance in saliva of $B$. burgdorferi infected ticks (Figs. 4B2-6). In mammals, A2M are known for their roles as broad-spectrum inhibitors of proteases and regulators of immune factors such as cytokine, IL-1, IL-6 and growth factors [58]. Whether or not tick A2Ms retain these functions remains to be investigated. There is limited evidence that tick A2M might regulate tick and pathogen interactions as suggested by up regulation of A2M in Rickettsia montanensis-infected D. variabilis ovaries indicating roles in transovarial transmission [59] and regulating phagocytosis of tick hemocytes indicates roles in tick immunity [60].

Of the 10 cystatins, two were enhanced (Figs. 4B7 and 11), two were unmodified (Figs. 4AB8 and 9), three were suppressed in B. burgdorferi infected ticks (Fig. 4B10), and three were only identified in B. burgdorferi infected ticks (S1 Table). There is evidence that cystatins play roles in tick and pathogen interactions [61]. Some of the tick cystatins have inhibitory activities against cysteine proteases and have immunomodulatory functions, which will be beneficial to transmitted B. burgdorferi [61]. One surprising finding in our data is that XP_029845674.1 (Fig. 4B10) which is Sialostatin-L2, an inhibitor of cathepsin-L, immuno-suppressant, and enhancer of $B$. burgdorferi proliferation in culture, was suppressed in saliva of $B$. burgdorferi infected ticks. On the other hand, XP_002434440.2 (Fig. 4B8), which is $100 \%$ identical to Sialostatin L, also an immuno-suppressant [61] was apparently not modified with $B$. burgdorferi infection.

Except for XP_002399667.1 (Fig. 4B14), TILs (Fig. 4B12, 15-24) were suppressed in B. burgdorferi infected tick saliva which suggests that they play a limited role(s) in $B$. burgdorferi transmission. Similarly, the single Kunitz type inhibitor in this study was suppressed in $B$. burgdorferi infected ticks and was present only in uninfected tick saliva throughout feeding (Fig. 4B12).

\section{Proteases}

Functional roles of proteases have been linked to several aspects of tick physiology [62-66] and transmission of tick-borne disease agents [67]. In this study, we found 58 proteases in saliva of uninfected and B. burgdorferi infected I. scapularis nymphs (Fig 4c). Consistent with published data in adult $I$. scapularis tick saliva proteome [24], majority of proteases in saliva of $I$. scapularis nymphs are metalloproteases (MPs) (38/58), followed by serine proteases $(12 / 58)$, cysteine proteases $(5 / 58)$, and 
aspartic proteases (3/58) (Fig. 4CA, CB, and CC, S1 Table). The $I$. scapularis genome encodes for at least 150 and 233 putatively inactive and active proteases, with majority being MPs, followed by serine proteases, cysteine proteases, aspartic proteases and threonine proteases [68]. Given that the I. scapularis genome encodes for more MPs followed by serine proteases, it is potentially possible that our findings here might be the consequence of the protease composition in I. scapularis genome. However, we are of the view that this might not be the case in that secretion of majority of proteases in this study were enhanced in saliva of B. burgdorferi infected ticks. Given the high number of protease sequences, we have separated secretion dynamics in three figures for M12B MPs (Fig. 4CA), non-family M12B MPs (Fig. 4CB), and non-MP proteases (Fig. 4CC).

Metalloproteases (MPs) Of the 38 MPs in this study, 21 are in family M12, two of which are in subfamily M12A (Figs. 4CA1 and 2) and the rest are in subfamily M12B (Figs. 4CA3-19). Please note that Fig. 4CA11 represents secretion dynamics of AAM93653.1 and $\mathrm{XP}_{-}$ 029826700.1, while Fig. 4CA17 represent XP 029835450.1 and XP_029883546.1. Non-family M12 MPs are in families M2 (Figs. 4CB1-4), M3 (Figs. 4CB57: please note that Fig. 4CB5 represent MOY36946.1, XP_029839442.1 and EEC16348.1), M13 (Figs. 4CB8 and 9), M20 (Figs. 4CB10 and 11, please note that Fig. 4CB10 represent XP_029841459.1 and MOY43909.1), and M49 (Figs. 4CB12-14).

The finding that majority of MPs in this study are in subfamily M12B that are structurally similar to snake venom MPs is interesting. Functional properties of snake venom MPs include hemorrhaging, degrading extracellular matrices, fibrinolysis, and inhibiting platelet aggregation [69]. Given that functions of snake venom MPs will promote tick feeding and dissemination of transmitted $B$. burgdorferi from the site of inoculation, it is logical that B. burgdorferi infected nymphs secreted these proteases at high abundance. It is notable that similar to snake venom functions, degradation of gelatin, fibrinogen, and fibronectin were reported in I. scapularis saliva [70]. Interestingly, the MP that were isolated from saliva and cloned by Francischetti et al., [70] (AY264367) is $100 \%$ identical to JC969 which was enhanced in response to B. burgdorferi infection in this study (Fig. 4CA3). Likewise, RNAi-mediated silencing of Metis 1 and Metis 2, which have $89 \%$ amino acid residue identity to AAM93652.1 (Fig. 4CA10) resulted in reduced fibrinogenolytic activity of $I$. ricinus saliva [71].

Non-metalloproteases proteases Non-metalloproteases include three aspartic proteases (AP, Figs. 4CC1 and 2, please note that XP_029849090 and MOY36011.1 are represented in Fig. 4CC1), five cysteine proteases (Figs. 4CC3-6; note that Fig. 4CC5 represent MOY36009.1 and MOY36012.1), and 12 serine proteases (Figs. 4CC7-17; note that Fig. 4CC14 represent XP_029825533.1 and XP_029825536.1). It is notable in Fig. 4CC that majority of non-metalloproteases were enhanced in response to infection suggesting the potential for these proteases to play roles in transmission of B. burgdorferi.

The 12 serine proteases in this study have features of subfamily S1 proteases that represent the core of mediators of the host defense system against tick feeding such as blood clotting, complement, and inflammation [7274]. Additionally, S1 proteases were more abundant in B. burgdorferi infected ticks, with four of these present only in B. burgdorferi infected ticks when compared to the uninfected ticks (Figs. 4CC7-17). From this perspective, it is conceivable that ticks might secrete S1 serine proteases to interfere with the host defense pathway. There is evidence that this might indeed be the case. A trypsin-like $\mathrm{S} 1$ serine protease that activates protein-C, was purified from saliva of adult I. scapularis [63]. Among other functions, activated protein-C regulates coagulation aimed at maintaining the fluidity of blood within the vasculature [75], which will be beneficial to both tick feeding and dissemination of transmitted $B$. burgdorferi. It is also interesting to note that serine protease phenoloxidase-activating factor 2 was secreted by infected ticks during the 12-72 $\mathrm{h}$ feeding time points, and only at the $48 \mathrm{~h}$ time point in uninfected ticks (Fig. 4CC14). Indirect data in insects [76-78]. suggest that phenoloxidase-activating factor 2 could be involved in the ticks' immune response to microbial infection. Data in bees also suggest that insect phenoloxidase-activating factor 2 is an activator of prothrombin and degrades fibrinogen to fibrin [79] if functional, the tick protein might interfere with the host blood-clotting defense in this way. Mammalian S1 serine proteases are also critical activators of protease-activated receptors (PARs), which are involved in signaling of host defense pathways [8082]. that the tick must suppress to successfully feed and transmit tick-borne disease agents. It is conceivable that serine proteases in this study might interact with signaling of PARs to interfere with the host response against tick feeding and host colonization by transmitted $B$. burgdorferi. A notable feature of serine proteases in this study is that majority were secreted highly by $B$. burgdorferi infected unfed ticks, except for five (Figs. 4CC7, 10,13 , and 14) that were secreted throughout the feeding process.

In addition to breaking down of peptides in lysosomes, cysteine proteases play important roles in induction and development of innate and adaptive immunity encompassing antigen-and pathogen-recognition and elimination, signal processing and cell homeostasis [83, 84]. 
Indirect evidence showing that cysteine proteases regulate key parasite pathogenesis [85-87] suggest the possibility that cysteine proteases identified here could aide transmitted $B$. burgdorferi to evade host immune defenses. It is interesting to note that four of the five cysteine proteases in this study were present in saliva of $B$. burgdorferi infected ticks only (Figs. 4CC3-6). Likewise, functional studies on tick aspartic proteases were limited to roles in physiology such as oocyte maturation and degradation of tick vitellin and host serum albumin [88]. The three aspartic proteases that were identified in this study were present only in $B$. burgdorferi infected tick saliva. Interestingly XP_0298490090.1 (Fig. 4CC1) shows $\sim 50 \%$ amino acid identity to an aspartic protease (KC540783.1) of the human itch mite (Sarcoptes scabei hominis) which degraded human hemoglobin, serum albumin, fibrinogen and fibronectin [89].

\section{Putative cholesterol and other lipid-binding proteins}

Figure $4 \mathrm{~d}$ summarizes the secretion dynamics of putative cholesterol and other lipid binding/interacting proteins. The six putative cholesterol binding proteins that show similarity to mammalian Niemann-Pick type C1 (NPC) (Fig. 4D1: represents XP_002435857.2 and XP 029829620.1) and MD-2-related lipid-recognition (ML) domain proteins (also known as NPC2) (Figs. 4D2-4, MOY44429.1, XP_002414779.2, and EEC18444.1 are represented by Fig. 4D4). The ML domain proteins (NPC2) can bind IgE [90] and microbial lipopolysaccharide (LPS) [91], and thus it will be interesting to investigate if proteins here interact with $B$. burgdorferi products. We also would like to note that XP 002435857.2 and XP_029829620.1 (Fig. 4D1) are highly identical except for an 11 amino acid deletion in the Cterminus region (not shown). Likewise, the NPC2 sequences MOY44429.1, XP_002414779.2, and EEC18444.1 (Fig. 4D4) are highly identical with amino acid differences restricted in amino-terminus region.

In mammals, interactions of NPC1 and NPC2 are required in transfer of cholesterol from lysosomes where currently two mechanisms are proposed: (1) NPC2 binds cholesterol which is transferred to NPC1 to be transported into cytosol and to the endoplasmic reticulum (ER), and (2) NPC1 directly binds to cholesterol and transfers it to NPC2 to be transported into the cytosol and to the ER [92]. Whether or not, this is the case for putative tick NPC1 and NPC2 remains to be ascertained. The mammalian NPC1 is 1300 amino acid residue with 13 transmembrane domains with an amino-terminus cholesterol-binding domain [93]. It is interesting to note that XP_029829620.1 and XP_002435857.1 (Fig 4D1) which are both annotated as NPC1 in GenBank have 274 and 286 amino acid residues, respectively, which is smaller than the human NPC1. It is notable that, the tick
NPC1 aligns with the amino-terminus cholesterolbinding domain of the mammalian NPC1 (not shown). Data mining in GenBank revealed that the I. scapularis genome encodes for other short NPC1-like proteins (XP_002435856.2, XP_002412172.1， XP_029830588.1 and XP_002402589.2) that were not found in tick saliva. We also would like to note that, I. scapularis also encodes for five other putative NPC1 (XP_029824526.1, XP_029824532.1, XP_029824537.1, EEC13272.1, and EEC08477.1) that are more than 1300 amino acid residues long and retain the secondary structure of the mammalian NPC1 but were not found in tick saliva.

The other lipid-binding proteins in Fig. 4d are annotated as putative fatty acid-binding proteins (Fig. 4D5), phosphatidylinositol-specific phospholipase C (Fig. 4D6) that participates in cell signaling through generation of second messengers: inositol 1,4,5-trisphosphate and diacylglycerol [94], and phospholipase B (Fig. 4D7 and 8) that play roles in signal transduction and inflammation through effects on metabolism of phospholipids and lysophospholipids [95]. The remaining lipid binding proteins include phosphatidylethanolamine-binding protein (Fig. 4D9) that is associated with lipid binding and serine protease inhibition [96] and has been shown to have antimicrobial function in Bombyx mori [97], and 3oxoacyl reductase (Fig 4D10 and 11) that is involved in fatty acid elongation [98] and has also been associated fatty acid biosynthesis in Plasmodium falciparum [99].

Although it is important to validate function, the finding that $B$. burgdorferi infection enhanced the secretion of cholesterol and other lipid-binding/interacting proteins by I. scapularis nymphs could be linked to B. burgdorferi transmission and colonization of the host. There is evidence that $B$. burgdorferi acquires cholesterol from the host and incorporates it as cholesterol glycolipids onto its membranes $[100,101]$. Based on these data, it is conceivable that the putative cholesterol and other lipidbinding/interacting proteins in this study might bind and present plasma lipids to transmitted B. burgdorferi for initial replication and dissemination from site of inoculation.

\section{Antimicrobial peptides (AMP)}

AMPs in tick saliva function to suppress bacteria growth at the tick feeding site and clear microbes in blood meal [54]. However, data in Fig. 4e show that putative AMPs in this study were suppressed (Figs. 4E1-5) in response to $B$. burgdorferi infection. This finding suggests that AMPs in this study might not be required for transmission of B. burgdorferi. This finding was surprising, as we would expect for the tick to secrete AMPs to prevent secondary bacterial infections at the feeding site. It is notable that in $B$. burgdorferi infected tick saliva, one AMP (EEC20127.1) was suppressed from 20-60-fold 
between 12-72 h tick-feeding periods when $B$. burgdorferi is likely transmitted [33, 34], but increased to comparable levels in saliva of replete fed ticks (Figs. 4E2). The observation that AMP levels were higher in replete fed (96-120 $\mathrm{h}$ fed) ticks, points to the possibility that secretion of AMPs was manipulated by B. burgdorferi transmission events, which ceased toward end of tick feeding when transmission was not active.

\section{Borrelia burgdorferi infection responsive histamine binding proteins/ lipocalins}

Lipocalins among other ligands can bind histamine and other molecules [102] and on this basis, lipocalins also referred to as tick histamine-binding proteins were postulated to play roles in tick evasion of host inflammation defense by binding histamine that is released at the tickfeeding site [103, 104]. It is notable that, of the eight lipocalins that were enhanced in saliva of B. burgdorferi infected ticks (Figs. 4F1-8), five were secreted within 12$24 \mathrm{~h}$ (Figs. 4F1-5) of tick attachment. This finding is interesting in that there is evidence that tick sensitivity to histamine declines as tick attachment stabilizes [105]. It is potentially possible that lipocalins that are secreted at high abundance during the first 12-24 h might sequester histamine and shield $B$. burgdorferi infected ticks from the deleterious effects of histamine during the attachment phase. We speculate that the two lipocalins that were secreted at high abundance in replete fed (96-120 h fed) infected ticks (Figs. 4F7 and 8) and those that were suppressed (Figs. 4F9-16) are not associated with transmission of B. burgdorferi. It is possible that cargo of lipocalins that were suppressed in infected ticks might be toxic against transmitted B. burgdorferi.

\section{Immune-related proteins}

We have identified 40 putative immune related proteins, seven of which were suppressed in B. burgdorferi infected ticks (SF5A and S1 Table). Some of the immunerelated proteins that were enhanced in saliva of $B$. burgdorferi infected ticks include four 14-3-3-phospho-binding proteins that regulate multiple signaling pathways including cancer, apoptosis, cell cycle progression, autophagy, glucose metabolism, and cell motility [97]. Another notable group of proteins are the novel E3 ubiquitin ligases (NEL) that might suppress patternrecognition triggered immunity as suggested by indirect evidence in some pathogenic bacteria evasion of immunity in plants [106]. If functional, the six of the seven tick NEL proteins that were enhanced in infected ticks will aide in colonization of the host by transmitted B. burgdorferi by suppressing pattern recognition triggered immunity.

Other findings include a peptidyl-prolyl cis-trans isomerase, which in microbes acts as virulence factor and a potential drug target [107] and annexin, which is being targeted in anti-parasitic therapeutics [108]. It is also interesting to note that there is indirect evidence that suggest that tick annexin might interfere in the host's complement defense against tick feeding and transmitted $B$. burgdorferi. Mammalian annexins can bind $\mathrm{C} 1 \mathrm{q}$ [109] and factor $\mathrm{H}$ [110], which respectively regulate the classical and alternative complement pathways. Since B. burgdorferi is sensitive to complement killing [111], is possible that tick annexin might serve as decoys to protect transmitted $B$. burgdorferi against complement killing. Other notable proteins enhanced with infection include immunoglobulin superfamily proteins that have been associated with immune regulation [112] and cyclophilin A was shown to enhance viral replication [113-115]. and it will be interesting to investigate the impact on transmitted B. burgdorferi at the tickfeeding site. Likewise, hemolectin is a haemocyte specific protein that is similar to von Willibrand factor and regulates hemolymph clotting and immunity in Drosophila $[116,117]$. In mammals, the toll-like receptor 9 protein plays roles in both innate immunity such as pattern recognition [109], and adaptive immunity [118, 119]. Therefore, it is interesting to note that toll-like receptor 9-like proteins were secreted at high abundance by B. burgdorferi infected ticks: there is a possibility that these proteins could interfere with functions of pattern recognition receptors on immune cells and aide in host colonization by transmitted B. burgdorferi.

\section{Borrelia burgdorferi infection responsive glycine rich proteins and extracellular matrix-like proteins}

Supplemental figures, SF5B and SF5C summarizes the secretion dynamics of 10 glycine rich proteins (GRP) and 45 putative extracellular matrix-like (ECM) proteins, respectively. Of the 10 GRPs, three were enhanced, two were unmodified, and the remaining five were suppressed in response to B. burgdorferi infection. Our annotation of GRPs as ECMs was based on the fact that these proteins play roles in formation of the amorphous adhesive substance (tick cement) that glues the tick to host skin [120]. Since tick cement will be required by both uninfected and infected ticks, the two GRPs (XP 029830864.1 and EEC14463.1) that were unmodified with $B$. burgdorferi infection could be associated with tick cement formation, while those that were enhanced or suppressed perform functions outside tick cement formation.

Indirect evidence suggests that some of the ECM proteins in this study might directly interact with $B$. burgdorferi. Available data show that $B$. burgdorferi encodes a fibronectin binding protein [121] and that binding of plasma fibrinogen aide spirochetes to circulate in the blood stream [122]. On this basis it is logical to assume 
that, fibronectin proteins that were enhanced in B. burgdorferi infected ticks might aide transmitted $B$. burgdorferi to disseminate from its site of inoculation. It is also interesting to note that $B$. burgdorferi enhances expression of adhesion molecules by endothelial cells [123], and thus it is possible that the neural cell adhesion molecules that were enhanced in infected ticks might interact with transmitted B. burgdorferi at the tick-feeding site to initiate dissemination.

Other notable ECM-like proteins include putative chitinases, which when active will degrade chitin. Active chitinases are characterized by the functional domain FDG(L/F)DLDWE(Y/F)P, where the bolded "D" and "E" amino acids are important for the chitinase function $[124,125]$. It is interesting to note that the functional domain is conserved in one of the five putative chitinases (XP_029843550.1) that were enhanced in infected ticks. This chitinase sequence show $53-65 \%$ amino acid identity to the $A$. americanum short and long chitinase isoforms (Accession \# AIR95100.1 and AIR95099.1), which when disrupted by RNAi silencing loosened the tick cement cone resulting in bleeding around the tick attachment site [126]. There is indirect evidence in other parasites that suggest that chitinases might promote $B$. burgdorferi colonization of the host as indicated Toxoplasma gondii chitinase modulated functions of macrophages and promoted establishment of the parasite [127].

\section{Housekeeping-like proteins}

Of the 747 proteins in this study, 355 belong to 15 housekeeping and housekeeping-like protein functional categories (SF5D-R). Although functional studies are needed to establish if housekeeping-like proteins in this study are functional, secretion patterns of some of the housekeeping-like proteins suggest that B. burgdorferi infection influenced secretion patterns of tick saliva proteins to its benefit. We developed commentary on housekeeping-like proteins to highlight putative roles in B. burgdorferi transmission.

Cytoskeletal (CS) A total of 98 CS proteins, 39 of which were suppressed with B. burgdorferi infection (SF5D). Majority of CS proteins that were enhanced in B. burgdorferi infected ticks were associated with actin function [128]. There is evidence that macrophage and dendritic cells phagocytosis of $B$. burgdorferi was actin dependent [129], while B. burgdorferi encoded actin was critical to its motility [130]. It will be interesting to investigate effect of tick actin on ability of macrophages and dendritic cells and on host colonization by transmitted $B$. burgdorferi.
Detoxification/Antioxidants The ticks' disruptive feeding style is expected to damage host tissues/cells that would accumulate reactive oxygen species (ROS) at the tick-feeding site. A total of 25 antioxidants were identified with majority $(n=16)$ being enhanced and the rest suppressed (SF5E). Notable in our data is the fact that $B$. burgdorferi, which is susceptible to toxicity of reactive oxygen species (ROS) including hydrogen peroxide $\left(\mathrm{H}_{2} \mathrm{O}_{2}\right)$ [131, 132], enhanced secretion of antioxidants that neutralize $\mathrm{H}_{2} \mathrm{O}_{2}$ and other ROS including catalase, thioredoxin, thioredoxin reductase, selenium, and glutathione S-transferase in B. burgdorferi infected tick saliva [133-135]. On the contrary copper/zinc superoxide dismutase, which produces $\mathrm{H}_{2} \mathrm{O}_{2}$ through catalyzing the two-step dismutation of superoxide radical $\left(\mathrm{O}_{2}{ }^{-}\right)$to $\mathrm{O}_{2}$ and $\mathrm{H}_{2} \mathrm{O}_{2}$ [136] was suppressed in saliva of $B$. burgdorferi infected ticks (SF5E). It is noteworthy that genes encoding for catalase and copper/zinc superoxide dismutase that were respectively enhanced and suppressed in $B$. burgdorferi infected saliva are absent in the $B$. burgdorferi genome [137]. There is evidence that $B$. burgdorferi resistance to oxidative stress is critical to their survival in the vertebrate host [131, 138-143]. In the vertebrate host, $B$. burgdorferi expresses different genes that mitigate the effects of the host's oxidative antimicrobial defense. Whether or not B. burgdorferi antioxidant genes are expressed in real time as it is transmitted to the host by the tick is unknown.

Hemelipoproteins/vitellogenin, and ferritin The secretion dynamics for hemelipoproteins and vitellogenin $(n=25)$ and ferritin $(n=2$, highly identical with differences in the amino-terminus region) are shown in SF5. Except for the two ferritins and three hemelipoproteins that were present only in B. burgdorferi infected tick saliva, the remaining 22 proteins were enhanced, suppressed or unchanged in abundance (ST1). It is interesting to note that 21 of the 22 proteins were enhanced within the first $24 \mathrm{~h}$ of feeding in B. burgdorferi infected tick saliva. This finding suggests that hemelipoproteins might not perform functions that are unique to B. burgdorferi transmission or that they could regulate critical tick feeding functions that are essential to both uninfected and $B$. burgdorferi infected tick feeding. It is noteworthy that ferritin was only detected in infected ticks suggesting a role in B. burgdorferi transmission. While other bacteria need host-derived iron to replicate $[144,145]$, there is evidence that $B$. burgdorferi does not require iron to replicate [146]. There is also evidence that B. burgdorferi that was loaded with iron was susceptible to killing by $\mathrm{H}_{2} \mathrm{O}_{2}$ and human polymorphonuclear leukocytes [147]. Given that ferritin is an iron storage protein [148], it could be feasible that $B$. burgdorferi infection induces high secretion of ferritin to sequester iron at the feeding 
site to protect the transmitted B. burgdorferi from irontriggered toxicity.

Metabolism associated proteins- nucleic acids We identified 11 nucleic acid metabolism proteins (SF5G), majority of which were enhanced in saliva of $B$. burgdorferi infected ticks. One of the enhanced nucleic acid metabolism proteins is $5^{\prime}$-nucleotidase, which in mammals catalyzes hydrolysis of extracellular nucleotides [149, 150] is also secreted into snake venom [151] and is an inhibitor of platelet aggregation [152]. Of note, inhibition of platelet aggregation is critical for ticks to complete feeding in that when small wounds occur, similar to tick feeding lesions, the host responds by forming a platelet plug at the injury site [153, 154]. Therefore, secretion of $5^{\prime}$-nucleotidase will likely aide in feeding success and transmission of B. burgdorferi.

Metabolism associated proteins- nuclear and transcriptional regulation proteins We also identified 11 putative histone proteins, five of which were enhanced in saliva of B. burgdorferi infected ticks (SF5H). Similarly, we also identified five transcription regulation proteins that were enhanced in infected ticks (SF5I). Beyond the role of histones in transcriptional regulation [155], extracellular histones are also associated with regulation of host defense including formation of neutrophil extracellular traps (NETs), involvement in inflammation response to injury, and thrombosis [156, 157]. Mice NETs had lethality against Borrelia afzelii but was not inhibited by addition of saliva of adult I. ricinus ticks that had completed feeding [158]. It will be interesting to investigate the impact of $B$. burgdorferi infection enhanced histones on NET defense against transmitted B. burgdorferi.

Metabolism associated proteins- amino acids It is interesting to note that all amino acid associated metabolism-associated proteins were enhanced in saliva of B. burgdorferi infected ticks. Given that B. burgdorferi does not encode for de novo synthesis of amino acids [137], it is notable that the amino acid metabolism associated enzymes (SF5J) that were enhanced in saliva of $B$. burgdorferi infected ticks are involved in catabolism of amino acid residues. For instance, fumarylacetoacetase is involved in tyrosine catabolism [159], and dihydropteridine reductase is associated with hydroxylation of the aromatic amino acids (phenylalanine, tyrosine and tryptophan) for biosynthesis of neurotransmitters: dopamine, and serotonin [160, 161]. Aspartate aminotransferase catalyzes a forward reaction to degrade amino acids, and reverse reaction to synthesize aspartate [162]. Likewise, D-3-phosphoglycerate dehydrogenase enzyme is involved in serine amino acid residue synthesis [163]. It is possible that some these enzymes might aide transmitted B. burgdorferi to assimilate amino acids that are released at the tick-feeding site.

Metabolism associated proteins- carbohydrate and energy We respectively identified 16 and 41 proteins that were categorized as carbohydrate and energy metabolism proteins, respectively (SF5K and SF5L). It is notable that all carbohydrate metabolism associated proteins were enhanced in B. burgdorferi infected ticks (SF5K). Similarly, except for eight proteins, all energy metabolism associated proteins were enhanced with infection (SF5L). B. burgdorferi encodes the complete glycolytic pathway [137] that uses exogenous glucose and other carbohydrates to produce its ATP [164-166]. There is evidence that $B$. burgdorferi infection of the vertebrate host leads to enhanced glycolysis in immune cells [167]. Thus, it is interesting to note that B. burgdorferi infection of $I$. scapularis nymph ticks resulted in enhanced secretion of key glycolysis/gluconeogenesis pathway enzymes. To gain further insight into impact of B. burgdorferi infection on glycolysis/gluconeogenesis, the secretion dynamics as revealed by NSAF values (index for relative abundance) of glycolysis/ gluconeogenesis pathway enzymes are represented in Fig. 5. In the glycolysis pathway, glucose or other sugars are utilized to produce energy adenine triphosphate (ATP) and nicotinamide adenine dinucleotide hydride (NADH) the molecules that are needed for normal cellular function. On the flip side, gluconeogenesis is the reverse process of glycolysis that utilizes non-carbohydrate materials to make glucose [168]. The most notable in our dataset is that 9 of the 10 glycolysis pathway enzymes were enhanced in saliva of B. burgdorferi infected ticks (Fig. 5). These include glucose- 6 phosphate-isomerase, fructose bisphosphate aldolase, and triosephosphate isomerase (Fig. 5) which represent the second, third, and last enzymes, respectively, in the first five-enzyme sequence that regulate the initial part of the glycolysis pathway referred to as energy consuming or preparatory phase. Interestingly, the complete set of the five enzymes that regulate the second part of glycolysis pathway referred to energy-producing phase: glyceraldehyde-3-phosphate dehydrogenase, phosphoglycerate kinase, phosphoglycerate mutase, enolase, and pyruvate kinase $[169,170]$ were secreted at high abundance by $B$. burgdorferi infected ticks (Fig. 5). Four enzymes: pyruvate carboxylase, phosphoenolpyruvate carboxykinase, fructose 1,6-bisphosphatase, and glucose 6-phosphatase are unique to gluconeogenesis pathway [171]. It is notable that fructose 1,6-bisphosphatase was secreted at high abundance by $B$. burgdorferi infected ticks (SF5L). Another notable observation in SF5K and SF5L is that all enzymes were 


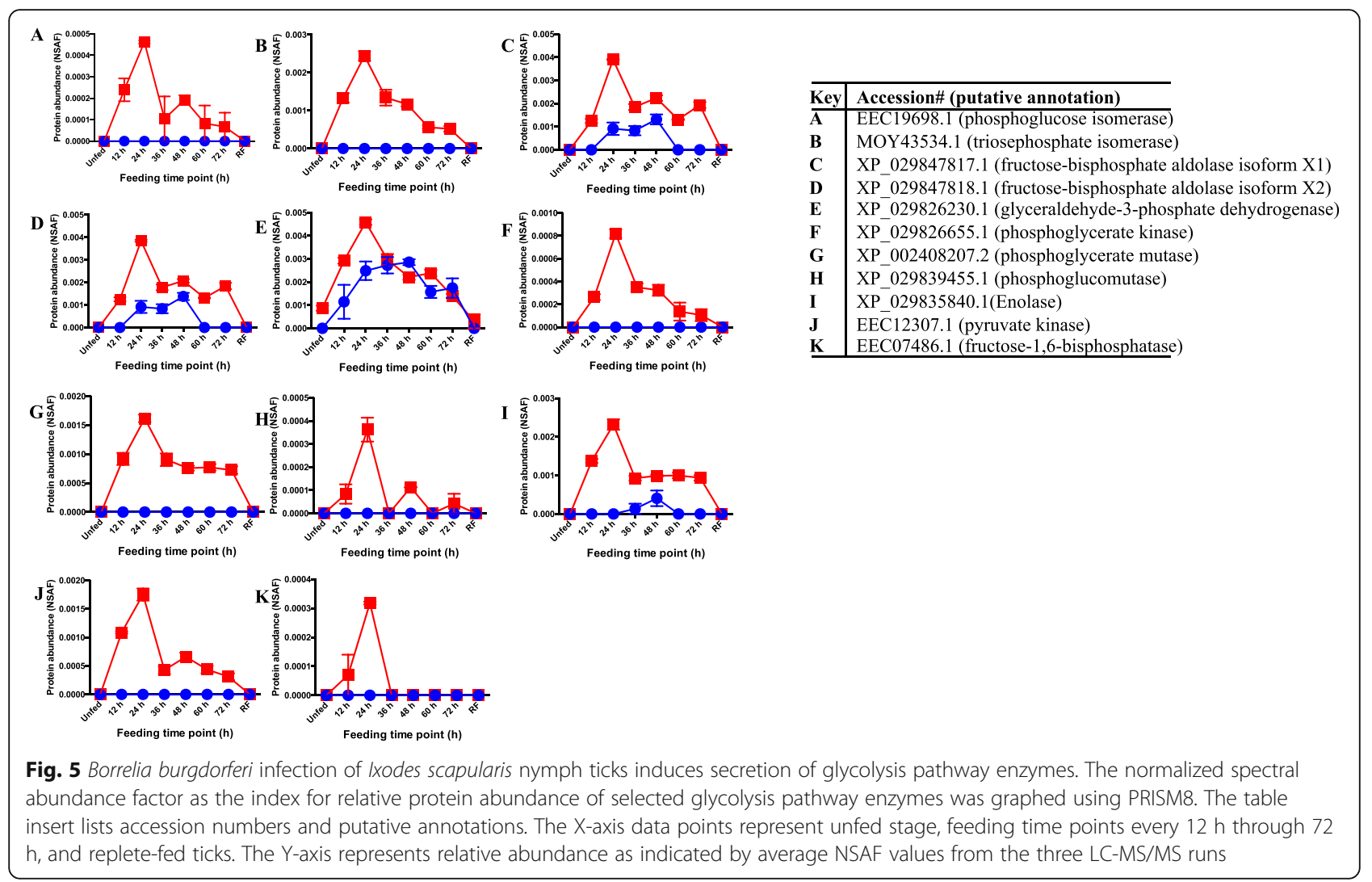

highly secreted at the 24-48 $\mathrm{h}$ feeding time point preceding major events of $B$. burgdorferi transmission [33, 34].

Previous studies have shown that pyruvate can protect B. burgdorferi from $\mathrm{H}_{2} \mathrm{O}_{2}$ toxicity [172]. Thus, it is interesting to note that pyruvate kinase which catalyzes the last step of the glycolysis pathway yielding pyruvate and one molecule of ATP [173] was enhanced in B. burgdorferi infected saliva (Fig. 5). If functional in the extracellular space, both pyruvate and the synthesized ATP will benefit the transmitted $B$. burgdorferi from $\mathrm{H}_{2} \mathrm{O}_{2}$ toxicity. Another notable enzyme that was enhanced in saliva of infected ticks is alpha L-fucosidase: this enzyme cleaves off the fucose sugar molecule during the break down of complex sugars [174]. If functional, it is conceivable that alpha L-fucosidase might provide $B$. burgdorferi with access to simple carbohydrates that are yielded in degradation of complex sugars at the tickfeeding site. The B. burgdorferi encoded glycolysis pathway will then process these simple sugars to produce ATP needed by the transmitted B. burgdorferi.

Protein metabolism associated- heat shock proteins and others We identified 60 protein metabolism associated proteins in six functional categories, majority of which were secreted at high abundance by infected suggesting roles in transmission of $B$. burgdorferi. The five functional categories include, protein modification associated $(n=23, \mathrm{SF} 5 \mathrm{M})$, protein export $(n=5, \mathrm{SF} 5 \mathrm{~N})$, protein synthesis $(n=9, \mathrm{SF} 5 \mathrm{O})$, and proteasome machinery $(n=9$, SF5P), and transporter/receptor $(n=9$, SF5Q). The finding that housekeeping proteins (HSP) were secreted at high abundance by infected ticks is notable. There is evidence that B. burgdorferi secreted putative HSP are involved in regulating the spirochete's interactions with its mammalian host immunity [175, 176]. Under normal physiology, HSPs are best known for their intracellular roles as stress response proteins and protecting cells from damage under stressful conditions $[177,178]$. On the other hand, when secreted into the extracellular space, HSPs serve as alarm signals to the immune system and triggers injury repair responses including anti-inflammation [178]. Whether or not tick HSPs in this study are functional, remains to be determined. However, if functional, it is conceivable that tick HSPs might promote transmitted B. burgdorferi colonization of the host by serving as inhibitors of host inflammation response to tick feeding. It is interesting to note that similar to findings in this study, there is evidence that tick HSPs were enhanced or interacted with pathogens in ticks that were infected with tick-borne disease agents; Anaplasma phagocytophilum [29, 179, 180], and Babesia bigemina [181] and mammalian cell interaction with Crimean-Congo hemorrhagic fever virus [182, 183]. Interestingly, there is evidence that $I$. 
scapularis HSP70 (XP_002433656.1) in this study contributed to tick fibrinolysis activity [182, 184], which will promote B. burgdorferi dissemination.

Signal transduction We identified 41 putative signaling/ cell function associated housekeeping proteins that were responsive to B. burgdorferi infection (SF5R). Among proteins described here, calreticulin (CRT), which in mammals is a cytosolic protein that binds calcium, protein, and mRNA [184], is the most studied in tick physiology. Tick CRT is an immunogenic tick saliva protein that is currently used as the biomarker for tick bites [185-188]. There is also evidence that tick CRT is involved in regulating interactions between ticks and tick-borne disease agents in that RNAi silencing of tick CRT reduced the Babesia bigemina parasite load in $R$. annulatus [188]. We have previously shown that $A$. americanum tick CRT can bind C1q, which is part of the $\mathrm{C} 1$ complex, which activates the classical complement pathway [189]. Interestingly, tick CRT binding of $\mathrm{C} 1 \mathrm{q}$ did not block complement activation, but it rather enhanced as addition of increased amounts of tick CRT resulted in increased deposition of the membrane attack complex. It is potentially possible that tick CRT serves as an activator of the classical complement pathway, and thus could serve as a decoy during B. burgdorferi transmission. It will be interesting to determine if the $\mathrm{C} 1$ complex preferentially deposits onto tick CRT than B. burgdorferi complement binding proteins. There is evidence that evasion of the classical complement pathway is required to regulate spirochetemia in mice [111]. It is also notable that while uninfected adult ticks secrete CRT during feeding $[2$, 24], CRT was secreted at detectable levels by $B$. burgdorferi-infected $I$. scapularis nymphs, but not the uninfected nymph. It will be interesting to investigate how tick CRT might protect B. burgdorferi from complement killing. Another interesting group of proteins are insulin growth factor binding proteins-related proteins (IGFBP-rP), which are part of the insulin and insulin-like growth factor signaling, which regulates multiple functions including immunity [190]. We found five IGFBP-rP sequences, three of which were suppressed, and two that were enhanced. We have recently shown that some of the tick IGFBP-rPs, which bind insulin [191], are involved in tick evasion of host inflammation defense [192]. Interestingly, RNAi silencing mediated disruption of A. americanum IGFBP-rP1 and IGFBPrP6S and L significantly affected tick fitness and feeding success [193] demonstrating the significance of this protein in tick feeding physiology.

\section{Tick-specific proteins of unknown function}

Tick specific proteins of unknown function are so called because they did not match to proteins of other organisms in GenBank. We identified a total of 138 tick specific proteins, of which more than 70 were suppressed in response to B. burgdorferi infection (SF5S). Some of the most notable highlights in the data is the fact that nearly all tick salivary peptide group 1 and basic tails were suppressed in infected ticks. Very little is known about tick specific proteins in this study with exception of the AV422-like (XP_002406260.1), which is an A. americanum homolog that was highly up regulated in ticks that were stimulated to start feeding [194, 195] and might be considered as a marker for tick preparedness to start feeding. Thus, it is notable that the secretion level of XP_002406260.1 was not affected by B. burgdorferi infection suggesting that this protein regulates critical tick feeding functions. Interestingly, RNAi silencing of AV422 prevented A. americanum ticks from feeding to repletion [195].

Secretion dynamics of rabbit proteins in saliva of Borrelia burgdorferi infected ticks Host derived proteins have been previously identified in tick saliva proteomes during tick feeding [24-26]. In this study, a total of 253 host-derived (rabbit) proteins were identified in saliva of $I$. scapularis uninfected and B. burgdorferi infected nymph saliva during feeding (ST1). The 253 host derived proteins were provisionally annotated into 21 functional categories. Of these, 12 (protease, protease inhibitors, keratin, metabolism of carbohydrates and energy, fibrinogen, signal transduction, globin/ RBC, transporter/ receptors, heme/ iron binding, lipocalin, and immune related proteins) were more abundant in saliva of $B$. burgdorferi infected ticks during feeding, four (metabolism of lipids, protein synthesis, transcription machinery, and nuclear regulation) were more abundant in uninfected tick saliva, and five (proteasome machinery, detoxification/ antioxidant, extracellular matrix, protein modification, and cytoskeletal) were variable in abundance or unchanged (SF6).

Presence of rabbit proteins in tick saliva might be dismissed as contamination. However, evidence in our data suggest that secretion of some the rabbit protein in tick saliva was influenced or induced by $B$. burgdorferi infection as indicated by the fact that majority of host proteins (52\%) were secreted in B. burgdorferi infected ticks compared to $12 \%$ in uninfected ticks, and $36 \%$ in both treatment groups (ST1). It is interesting to note that the proteins in the 12 functional categories that were more abundant in $B$. burgdorferi infected tick saliva were present within the first $12 \mathrm{~h}$ of tick attachment, which could indicate role(s) of these proteins in conditioning the hosts' feeding site for transmission of B. burgdorferi. It is noteworthy that except for the $12 \mathrm{~h}$ time point when protease inhibitors were secreted at low abundance by uninfected ticks, host derived proteases and protease inhibitors were present only in B. burgdorferi infected saliva (ST1) further demonstrating the impact 
of infection on secretion of rabbit proteins. Although present in both uninfected and B. burgdorferi infected tick saliva, the detoxification/antioxidant and extracellular matrix proteins were more abundant in uninfected ticks up to the first $24 \mathrm{~h}$ and then switched to abundance in saliva of infected ticks in the subsequent time points (SF6). As majority of B. burgdorferi transmission occurs around $48 \mathrm{~h}$, tick saliva proteins that are reverted in abundance during feeding by $B$. burgdorferi infected ticks indicates that these proteins could play important roles in survival and facilitating transmission into the mammalian host. For instance, peroxiredoxin, which is absent in B. burgdorferi is an antioxidant of $\mathrm{H}_{2} \mathrm{O}_{2}$ and was identified only in $B$. burgdorferi infected tick saliva from 12-72 $\mathrm{h}$ of feeding (ST1) when transmission of the spirochete is expected [33, 45]. Since B. burgdorferi is sensitive to killing by $\mathrm{H}_{2} \mathrm{O}_{2}[131,132]$, it is logical to assume that rabbit peroxiredoxin secreted in tick saliva could protect transmitted B. burgdorferi. It is also interesting to note that fibrinogen, which is the precursor to fibrin that forms a fibrin-based blood clot at the site of injury, was present only in B. burgdorferi infected tick saliva. Given that B. burgdorferi outer surface protein $C$ (OspC), which binds fibrinogen [196] is up-regulated during spirochete transition from the midguts to the salivary glands [197], the finding that fibrinogen was secreted only in B. burgdorferi infected tick saliva could indicate its potential role(s) in transmission and dissemination through a hematogenous route.

\section{Borrelia burgdorferi infected ticks provoke robust anti-tick immunity after a single infestation.}

Figure 6 summarizes a significant finding in this study, that a single infestation of rabbits by $B$. burgdorferi infected $I$. scapularis nymphs provoked protective anti-tick immunity that resulted in high mortality of $B$. burgdorferi infected ticks during the second infestation compared to uninfected ticks. Prompted by our finding that B. burgdorferi infected ticks secreted more tick saliva proteins at high abundance than uninfected ticks, we sought to repeatedly infest rabbits to elicit immunity against $B$. burgdorferi infection specific tick saliva proteins. To our surprise, although we did not observe any significant differences in tick feeding efficiency during the first infestation, a significantly high number of $B$. burgdorferi infected ticks died during the second infestation. We repeated this study with a cohort of 8 rabbits (4 each, uninfected and infected) and observed mortality of $46.5-76 \%$ of $B$. burgdorferi infected ticks compared to $15-28 \%$ for the uninfected ticks during the second infestation (Fig. 6a). Likewise, though not statistically significant, the engorgement mass as index for amount of blood that was ingested by B. burgdorferi infected ticks that fed to repletion was apparently smaller than uninfected ticks (Fig. 6b).

Given the finding in Fig. 6, we were curious about antibody response to tick saliva proteins of uninfected and B. burgdorferi infected ticks (Fig. 7). We subjected protein extracts of whole uninfected and B. burgdorferi infected $I$. scapularis nymphs that fed on rabbits for 24 h (Fig. 7a), 48 h (Fig. 7b), and 72 h (Fig. 7c) to ELISA analysis using purified IgG of rabbits that were infested by uninfected (blue symbols) and B. burgdorferi infected (red symbols) ticks. Although not statistically significant as revealed by unpaired t-test, ELISA analysis shows that tick saliva proteins that elicited immunity against nymph tick feeding were apparently expressed at high level in $B$. burgdorferi infected ticks than uninfected (Fig. 7a-c). We would like to note that rabbit (antibody) 98 and 97 were infested once with uninfected and B. burgdorferi infected nymphs, respectively.

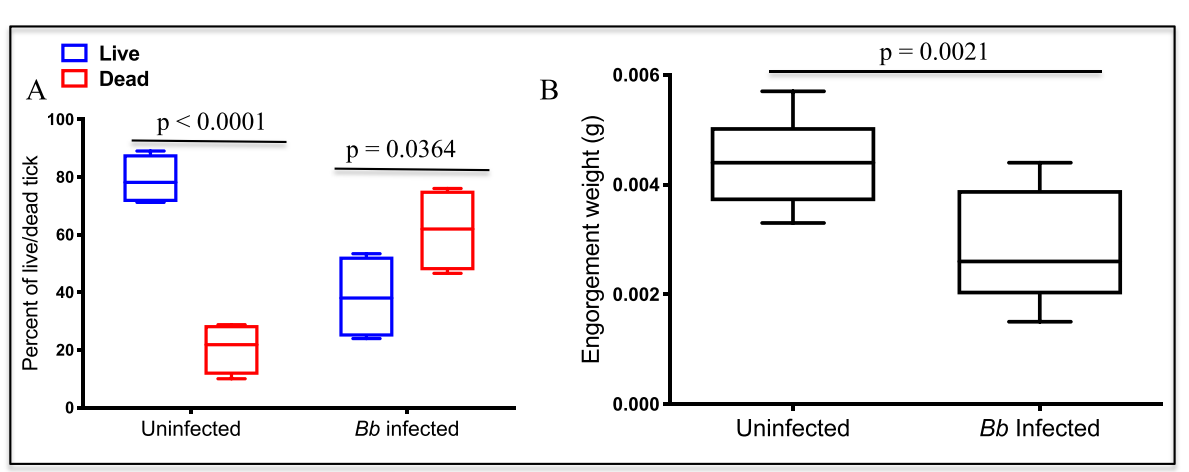

Fig. 6 Single infestation of rabbits with Borrelia burgdorferi infected Ixodes scapularis nymph ticks elicits immunity against tick feeding. Three weeks after the primary infestation, New Zealand white rabbits were re-infested with uninfected and $B b$ infected $I$. scapularis nymphs ( $n=75$ ). Tick feeding progress was monitored every $24 \mathrm{~h}$; all attached (representing live ticks [blue box]) and detached (representing dead ticks [red box]) were counted. a Cumulative average of ticks that fed on four rabbits ( $p$-value $<0.0001$ when comparing live and dead from uninfected; $p$-value $=0.0364$ when comparing live and dead from B. burgdorferi infected). $\mathbf{b}$ Mean engorgement weight $(\mathrm{mg})$ of replete fed ticks $(p$-value $=0.0021$ when comparing uninfected and B. burgdorferi infected). Unpaired t- test was used to determine statistical significance 


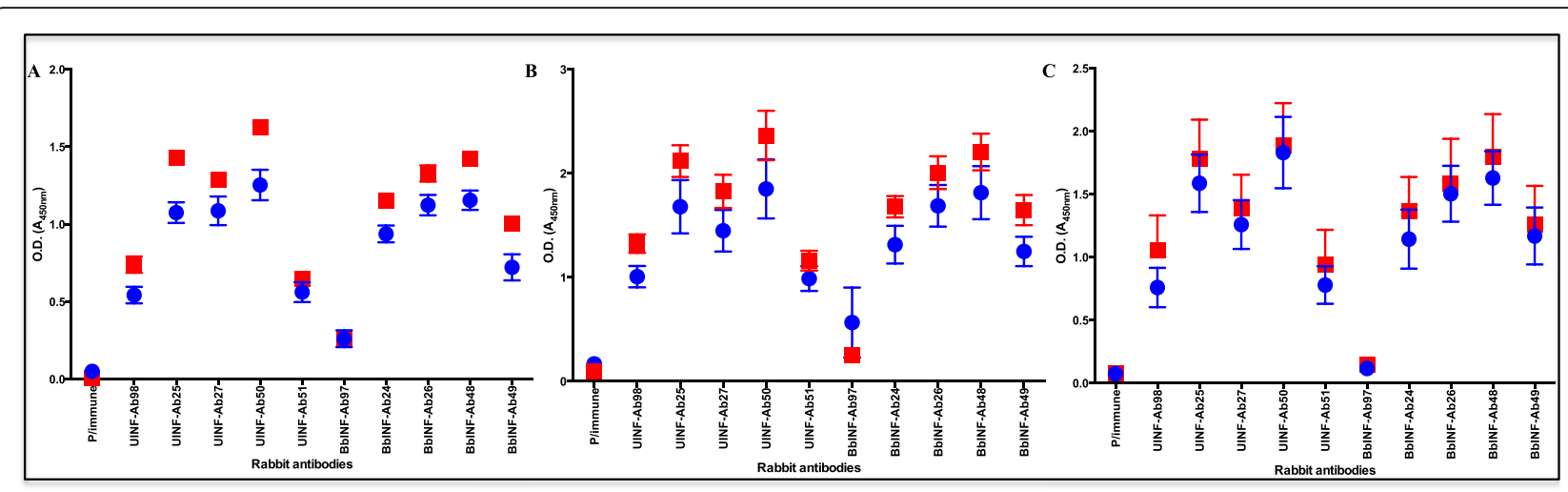

Fig. 7 Tick saliva proteins eliciting immunity against Ixodes scapularis nymph feeding are apparently highly expressed in Borrelia burgdorferi infected ticks than uninfected. Total tick protein extracts (500 ng per well) of uninfected (blue) and B. burgdorferi infected (red) I. scapularis nymphs that fed on rabbits for 24,48 , and $72 \mathrm{~h}$ were subjected to standard ELISA using purified $\mathrm{lgG}(100 \mu \mathrm{g} / \mathrm{mL})$ of rabbits that were exposed once (Ab97 and 98) or twice (Ab 24, 25, 26, 27, 48, 49, 50 and 51) to uninfected and infected ticks. Y-axis $=A_{450 n m}$, X-axis shows different rabbit antibodies. P/immune = pre-immune, UINF-Ab98, 25, 27, 50, and 51 = rabbit immune sera to tick saliva proteins of uninfected nymphs. BbINFAb97, 24, 26, 48, and 49 = rabbit immune sera to tick saliva proteins of $B$. burgdorferi infected nymphs. $A$, B, and $C=$ ticks that fed for 24,48 , and $72 \mathrm{~h}$ respectively

\section{Discussion}

This study has described tick saliva proteomes of uninfected and B. burgdorferi infected I. scapularis nymphs. Data here clearly demonstrate that $B$. burgdorferi infection influences $I$. scapularis nymph ticks to secrete a high number of proteins than uninfected ticks. Our strategy to identify tick saliva proteins secreted by unfed ticks, and of fed ticks every $12 \mathrm{~h}$ during feeding allowed us to relate the secretion dynamics to transmission biology of B. burgdorferi. These data will allow us to prioritize tick saliva proteins that are secreted prior to, or during major transmission events of $B$. burgdorferi $[33,34]$ in our quest to identify target antigens for vaccines to prevent LD.

Since at the unfed stage, B. burgdorferi is predominantly resident in tick midguts and transmission events ramps up after $48 \mathrm{~h}$ of tick attachment [33,34], it is logical to expect that $B$. burgdorferi might have no impact on protein composition in saliva of unfed ticks. Thus, it was interesting to note that we identified 75 more proteins in saliva of unfed B. burgdorferi infected than uninfected (Fig. 1). Given that B. burgdorferi infection of ticks in this study was done by capillary feeding, it is possible that an unusually high number of spirochetes than naturally infected ticks was delivered to midguts. If this is the case, it is plausible that some of the spirochetes might have migrated to the salivary glands impacting secretion dynamics of tick saliva proteins. It is also possible that the high number proteins secreted by unfed $B$. burgdorferi infected ticks might reflect the yet unknown impact of B. burgdorferi to condition the vertebrate host to physiology. We speculate that proteins identified in saliva of unfed B. burgdorferi infected ticks might be associated with conditioning of the host to promote $B$. burgdorferi colonization of the host. It is also notable that secretion of majority of tick saliva proteins by $B$. burgdorferi infected ticks ceased at the $72 \mathrm{~h}$ feeding time point when transmission of B. burgdorferi is expected to be completed or near completion [33, 34]. In contrast, replete fed (96-120 h fed) uninfected ticks secreted 124 more proteins than B. burgdorferi infected ticks (Fig. 1). Also, notable, functional categories that were enhanced in response to B. burgdorferi infection were secreted at the highest abundance during the first $24-48 \mathrm{~h}$ of tick feeding (Figs 2, 4, and 5; SF5), which precedes major B. burgdorferi transmission events that occur after the tick has attached for more than $48 \mathrm{~h}[33,34]$.

Although not yet demonstrated, evidence that flaviviruses might be sequestered into exosomes during transmission [198] indicates that tick exosomes are secreted into the host during tick feeding. Multiple tick saliva proteins that were enhanced in saliva of $B$. burgdorferi infected ticks have been reported in mammalian and parasite exosomes [198-203]. For instance, serpins were reported in mammalian exosomes [199, 200], while cysteine proteases, fatty acid-binding protein, housekeeping-like proteins such as HSP and actin, glycolysis/gluconeogenesis enzymes such as enolase, antioxidants such as thioredoxin, and glutathione S-transferase were reported in helminth parasite exosomes [202, 203]. This might suggest the possibility that some of the tick saliva proteins that were secreted at high abundance in saliva of B. burgdorferi infected ticks might be associated with tick saliva exosomes.

It is important to acknowledge the limitation of this study. The most significant is that B. burgdorferi infected ticks used in this study were artificially infected. There is potential that ticks used in this study might have contained more spirochetes than what is normally observed 
in naturally infected ticks, and this might have affected secretion of some of the tick saliva proteins in this study. In future studies, it will be imperative to validate our findings in naturally $B$. burgdorferi infected ticks by feeding larvae on B. burgdorferi infected hosts and then validating protein secretion in molted infected nymphs. It is also important to note that we did not include a killed B. burgdorferi control. This treatment might have revealed tick saliva proteins in this study that could be present due to stress response. However, we are encouraged by findings in this study that the secretion dynamics of some of the proteins were not affected by $B$. burgdorferi infection of ticks. Of note we found that proteins for which secretion dynamics was unaffected by $B$. burgdorferi infection included homologs to AV422 and tick IGFBP-rP1; which we previously found among tick proteins that were enhanced in ticks that were stimulated to start feeding: on cattle [194], rabbits, dogs, and humans [22]. Therefore, the observations that AV422 and IGFBP-rP1 were unaffected by B. burgdorferi infection demonstrated the importance of these proteins in regulating tick feeding functions of both uninfected and B. burgdorferi infected ticks.

Another limitation of this study is the fact that ticks feeding on different hosts might utilize different tick saliva proteins. We have previously shown that both Amblyomma americanum and I. scapularis have different tick saliva protein profiles when stimulated to start feeding on different hosts [22]. Although there is a core set of proteins that are secreted into tick saliva regardless of the host [22], it is potentially possible that some of the tick saliva proteins identified in this study might not be secreted if ticks are fed on different host such as rodents or humans.

It is also important to note that several Borrelia spp and strains have been described [199], and it is potentially possible that tick saliva protein profiles will change depending on the species and/or strain of the infecting spirochete. Here, we used the wild type B. burgdorferi strain 31 MSK5 isolate which contains all relevant plasmids that promote infectivity [200]. Therefore, there is a high likelihood that majority of tick saliva proteins in this study will be associated with transmission of $B$. burgdorferi to humans.

\section{Conclusions}

Given that I. scapularis nymphs transmits B. burgdorferi to majority of humans, data here provides the foundation upon which a tick-antigen based vaccine to prevent LD can be developed. Comparative analysis between uninfected and B. burgdorferi infected nymph tick saliva proteomes allowed us to identify three categories of tick saliva proteins: (i) enhanced, (ii) unmodified, or (iii) suppressed in response to $B$. burgdorferi infection. We speculate that tick saliva proteins that were enhanced in saliva of $B$. burgdorferi infected ticks play significant roles in transmission of B. burgdorferi and represent important targets for developing tick antigen-based vaccines to LD. Equally important, tick saliva proteins that were unmodified with $B$. burgdorferi infection likely regulate key tick feeding functions, which if blocked will disrupt feeding physiology and prevent transmission of B. burgdorferi. Lastly, we think that tick saliva proteins that were suppressed in response to B. burgdorferi infection are likely not good targets for tick vaccine development. However, some of these proteins might have lethality against transmitted $B$. burgdorferi and thus might be a source for design of novel anti-B. burgdorferi therapeutics.

\section{Methods}

\section{Ethics statement}

All experiments were done according to the animal use protocol approved by Texas A\&M University Institutional Animal Care and Use Committee (IACUC) (AUP 2017-0068 and 2018-0001) that meets all federal requirements, as defined in the Animal Welfare Act (AWA), the Public Health Service Policy (PHS), and the Humane Care and Use of Laboratory Animals. This study used 12 rabbits, all of which were processed for terminal bleed collections under general anesthesia as approved by the AVMA (American Veterinary Medical Association) and adopted by Texas A\&M University IACUC.

\section{Infecting lxodes scapularis nymphs with Borrelia burgdorferi}

Ixodes scapularis nymph ticks used in this study were purchased from the tick laboratory at Oklahoma State University (Stillwater, OK, USA). Ixodes scapularis nymphs were infected with $B$. burgdorferi ( $>1 \times 10^{7}$ cells/ $\mathrm{ml}$ ) cultured in BSK-H (Sigma-Aldrich, St Louis, MO) complete media supplemented with $6 \%$ rabbit serum by capillary feeding methods using as described with modifications [35]. The wild type B. burgdorferi strain 31 MSK5 isolate that was used in this study contains all relevant plasmids for infectivity [204] and was initially isolated from tick midguts [205]. The B. burgdorferi (strain B31 clone MSK5) that was used in this study was kindly gifted by Dr. Jon T. Skare (TAMU Health Science Center) and was routinely propagated in BSK-H complete media. To prepare B. burgdorferi for feeding to nymphs, $10 \mathrm{~mL}$ of BSK-H culture of log-phase spirochetes were pelleted at $300 \mathrm{~g}$ for $10 \mathrm{~min}$ at room temperature (RT) and then re-suspended in $1 \mathrm{~mL}$ of fresh BSK-H media to yield $>1 \times 10^{7}$ cells $/ \mathrm{ml}$. To prepare the feeding unit, a sterile $10 \mu \mathrm{L}$ pipette filled with $5 \mu \mathrm{L}$ of the B. burgdorferi concentrated culture was taped onto a glass slide. Under a dissecting scope, the tick's 
mouthpart was inserted into the pipette tip opening. To prevent ticks from dislodging, the feeding unit was inserted into another modified pipette tip as shown in SF1A. Based on an empirically determined timeline, nymphs attached to the feeding unit were incubated in a humidified chamber in an incubator at $32^{\circ} \mathrm{C}$ with $1 \%$ $\mathrm{CO}_{2}$ for 1-2 $\mathrm{h}$ to allow for feeding to complete. After feeding, ticks were kept at $22-24^{\circ} \mathrm{C}$ with $\sim 90 \%$ humidity for one week to allow for B. burgdorferi to adapt to the tick environment before proceeding to tick feeding on rabbits and collecting tick saliva (detailed below).

Routinely, for every batch of B. burgdorferi-infection, $10 \%$ of ticks were processed to confirm B. burgdorferi infection using flaB gene primers [206]. Ticks were disinfected by rinsing with $1 \%$ bleach, $70 \%$ ethanol, and water (repeated 3X for each solution) and then individually processed for genomic DNA extraction using the DNAeasy Blood and Tissue Kit (Qiagen, Hilden, Germany). The genomic DNA was used in qualitative PCR using flaB gene (GenBank: KR782218.1) forward (5'-CACATATTCAGATGCAGACAGAGGTTCTA-3') and reverse (5'- AATTGCATACTCAGTACTATTCTT TATAGAT-3') primers. We did not proceed with saliva collection (described below) if infection was below $80 \%$. Subsequently, we collected sera of infested rabbits to validate transmission of $B$. burgdorferi by ELISA and western blotting analyses of laboratory cultured tick extracts.

\section{Collecting Ixodes scapularis nymph tick saliva}

Uninfected or $B$. burgdorferi-infected I. scapularis nymph ticks were fed on 10-12 weeks old New Zealand white female rabbits $(n=2$ per treatment group for total of 4, Harlan Sprague Dawley Inc., Indianapolis, IN, USA). Tick feeding was done as published [54] and approved in animal use protocols 2017-0068 and 20180001. Ticks were restricted to feed on top of the rabbit ear using the two-inch cotton stockinet tick containment cells that were glued onto rabbit ears using the Kamar adhesive (Kamar Products Inc., Zionsville, IN, USA). Given the small size of nymphs, the tick containment cell was lined with Pantyhose material to prevent ticks from escaping. Saliva was collected from uninfected and B. burgdorferi-infected $I$. scapularis unfed nymphs ( $n=$ $50)$ and partially fed nymphs ( $n=30$ per time point) for $12,24,36,48,60$, and $72 \mathrm{~h}$ (manually detached), and replete fed nymphs $(n=15)$ ticks. To collect tick saliva, we first aspirated $5 \mu \mathrm{L}$ of $2 \%$ pilocarpine-PBS solution into a $10 \mu \mathrm{L}$ pipette tip, which were subsequently taped onto a glass slide. Under a dissecting scope, tick mouthparts were inserted into pilocarpine-PBS solution in the pipette tip as illustrated in SF1. To secure the nymph during saliva collection, a protective cap was prepared by modifying a $10 \mu \mathrm{L}$ pipette tip. The tick saliva collection unit was then placed in humidified chamber at RT for 4 h (empirically determined during preliminary studies) with visual inspection every 30 min to check for disengaged ticks.

\section{LC-MS/MS analysis of tick saliva proteins}

I. scapularis nymph tick saliva proteins were identified using LC-MS/MS analysis as previously described [22, 24, 26]. Approximately $2 \mu \mathrm{g}$ of total tick saliva proteins (in triplicate) per feeding time point was processed using LC-MS/MS. Briefly, proteins were digested overnight at 37C using trypsin (Promega, Madison, WI, USA) at 1:20 (enzyme:protein) ratio in $2 \mathrm{M}$ urea/0.1M Tris $\mathrm{pH} 8.5,1$ $\mathrm{mM} \mathrm{CaCl} 2$ reaction buffer. Subsequently, the digested peptides were processed for LC-MS/MS analysis [22, 24, 26] using the nanoflow liquid chromatography mass spectrometry using a $\mathrm{Q}$ Exactive mass spectrometer (Thermo Fisher Scientific).

\section{Identification of tick saliva proteins}

Tandem mass spectra that was extracted using the RawExtract 1.9.9.2 [207] were searched against the protein database using ProLuCID in the Integrated Proteomics Pipeline [208]. The protein database was assembled from protein sequences of tick and spirochete (GenBank), rabbit (Uniprot), and decoys (reverse sequences of all entries). Redundancies in the database were eliminated at $98 \%$ amino acid identity using the CD-hit program [209]. With false discovery rate (FDR) set to $1 \%$ hit to decoys, proteins with at least two six residue peptides hits in 2 of the 3 runs were accepted. Results were post processed to only accept peptide/spectrum matches (PSM) with $<10 \mathrm{ppm}$ precursor mass error. Finally, the Identification Compare (IDcompare) program on IP2 Pipeline [208] was used to combine protein matches from each time points into one file.

For annotation of tick proteins were searched against multiple databases including GenBank, Uniprot [210], MEROPS database [42], conserved domains at NCBI, and SWISS-MODEL homology modeling at ExPASY [211]. The outputs from the blast searches were loaded into the classifier program in Dr. Jose M. Ribeiro's visual basic program [212] for functionally categorization.

\section{Graphic visualization of secretion dynamics of Ixodes scapularis tick saliva proteins}

The normalized spectral abundance factors (NSAF), which is validated to estimate relative abundance in label-free quantification in LC-MS/MS analysis of protein [38-40] was used to determine relative abundance of proteins at every time point. To gain insights into secretion dynamics of functional categories, NSAF sum totals expressed as percentage for each functional category were normalized using Z-score statistics as described 
[22, 24, 26]. Subsequently, heatmaps of normalized percent NSAF were generated using the heatmap2 function in gplots library in $\mathrm{R}$ [41]. The secretion dynamics (low to high abundance) were used to assemble clusters on heatmaps. To gauge insight into secretion dynamics of the individual proteins, average NSAF values (at least two of the three runs) of individual proteins were graphed using PRISM 8 (GraphPad Software, San Diego, CA).

\section{Effect of repeated infestation on tick feeding success}

This experiment was prompted by findings in this study that $B$. burgdorferi infected nymphs were secreting more proteins at high abundance than uninfected ticks. Our goal was to provoke high antibody titers to tick saliva proteins that were secreted by $B$. burgdorferi infected ticks. To our surprise, we observed significantly high mortality of B. burgdorferi infected ticks during the second infestation than the uninfected. To validate these observations, eight rabbits divided in two cohorts of four rabbits each were repeatedly infested twice three weeks apart with uninfected and B. burgdorferi infected ticks ( $n=70$ per rabbit). Tick attachment was confirmed after $24 \mathrm{~h}$ and all unattached ticks were removed. Thereafter, live (attached and feeding) and dead ticks (detached) were counted every $24 \mathrm{~h}$. We calculated the mortality rate as a percentage of dead ticks over ticks that were confirmed attached at $24 \mathrm{~h}$ after ticks were placed on rabbits. Ticks that completed feeding were weighed individually to determine the engorgement mass as index for amount of blood that was ingested. Rabbit blood collections were obtained before tick infestation (pre-immune) and after completion of uninfected and B. burgdorferi infected tick feeding every week for 4 weeks. Sera was used to confirm if rabbits seroconverted by western blot and ELISA analyses.

\section{ELISA to quantify immunogenic tick saliva protein expression}

Prompted by findings of high mortality of B. burgdorferi infected ticks during second infestation, we sought to investigate antibody titers to tick saliva proteins in rabbits that were infested by uninfected and B. burgdorferi infected ticks using standard ELISA. Total proteins of whole uninfected and B. burgdorferi infected ticks (pools of 10 ticks per time point): unfed and fed on rabbits for 24,48 , and $72 \mathrm{~h}$ were minced using soft tissue scissors and processed for total protein extraction by sonication on ice in denaturing buffer (8M Urea, $100 \mathrm{mM}$ Tris, 150 $\mathrm{mM} \mathrm{NaCl}, 1 \%$ SDS, 5mM DTT, pH 7.4). After centrifugation to pellet non-dissolved tissues, the supernatant was filter sterilized $(0.2 \mu \mathrm{m})$ and used for total protein quantification using the BCA method (Thermo Scientific). Prior to BCA quantification, the samples were diluted 50-fold to reduce the potential background from Urea, SDS, and DTT.

A 96-well plate was coated with $500 \mathrm{ng}$ of total whole tick protein per well and subjected to standard ELISA analysis using purified $\mathrm{IgG}(100 \mu \mathrm{g} / \mathrm{ml})$ of rabbits that were infested with uninfected or B. burgdorferi infected I. scapularis nymphs, followed by goat anti-rabbit IgGHRP secondary antibody (1:5000). Using purified IgG allowed us to utilize equivalent amount of antibody in our ELISA and get insight into relative antibody titer levels. Purification of IgG was done using the protein G column according to instructions by the manufacturer (GE Healthcare). The positive signal was detected using the 1-Step Ultra TMB-ELISA substrate (Thermo Scientific). With background removed, OD in triplicate were plotted in PRISM 8.

\section{Validate tick transmission of Borrelia burgdorferi to rabbits}

To validate if ticks artificially infected by capillary feeding were transmitting to rabbits, lab cultured B. burgdorferi was subjected to standard ELISA and western blotting analysis. The second passage of B. burgdorferi culture was harvested by centrifugation at $300 \mathrm{~g}$ for 10 min at RT. Following washing of the pellet in phosphate buffered saline (PBS) to remove excess culture media components, total B. burgdorferi proteins was extracted by sonication in PBS on ice. The supernatant was filter sterilized $(0.2 \mu \mathrm{m})$ and quantified using the BCA method (Thermo Scientific). Subsequently, 1 and $3 \mu \mathrm{g}$ of total $B$. burgdorferi protein extract was respectively subjected to ELISA and western blotting analyses using purified immune IgG. For western blotting analysis, B. burgdorferi protein extract was resolved on a $10-20 \%$ Tris-Glycine SDS-PAGE and transferred onto a PVDF membrane. After blocking in 5\% skim milk in PBS w/ Tween-20 $(0.05 \%)$, the plates or membranes were exposed to the purified IgG $(10 \mu \mathrm{g} / \mathrm{ml})$ from pre-immune and immune sera of rabbits that were infested by uninfected ticks $(n=$ 5 ) and B. burgdorferi infected $(n=5)$. To visualize the positive signals, a goat anti-rabbit IgG-HRP secondary antibody (1:5000) and 1-Step Ultra TMB-ELISA substrate (Thermo Scientific) or SuperSignal West Femto Maximum Sensitivity Substrate (Thermo Scientific) were used.

\section{Supplementary Information}

The online version contains supplementary material available at https://doi. org/10.1186/s12864-021-07429-0.

Additional file 1: SF1. Non-invasive method of collecting saliva from Ixodes scapularis nymphs. Tick saliva collections were performed using a $10 \mu \mathrm{l}$ pipette tip set up. A modified $10 \mu \mathrm{l}$ pipette tip was used to affix the tick mouthpart in the solution and restrict the tick from escaping. Saliva collections from ticks were not included if leakage of fluid was detected 
around the protective cap. SF2. Antibody response to Borrelia burgdorfer antigens by ELISA and western blotting analyses. Total protein extracts from B. burgdorferi (1 or $3 \mu \mathrm{g}$ ) were coated per well for ELISA (A) or resolved by SDS-PAGE for western blotting (B) analyses using purified lgG $(10 \mu \mathrm{g} / \mathrm{ml})$ from pre-immune (PI), rabbit antibody (Ab) numbers 98,25 , 27,50 and 51 from rabbits that were infested with uninfected nymphs and $A b$ numbers $97,24,26,48$, and 49 from rabbits that were infested with $B$. burgdorferi infected nymphs. For ELISA, the $y$-axis represents the $A_{450}$ and $x$-axis represent the rabbit number. SF3. Profile of uninfected and Borrelia burgdorferi infected Ixodes scapularis nymph tick saliva proteins during feeding. Uninfected and B. burgdorferi infected I. scapularis nymph ticks that were unfed, partially fed for $12,24,36,48,60$, and $72 \mathrm{~h}$, and replete-fed, were stimulated to salivate by injecting $2 \%$ pilocarpine into hemolymph. Saliva was electrophoresed on a 10-20\% acrylamide ge and silver stained. Please note the molecular weight ladder from 10$250 \mathrm{kDa}$. SF4. Secretion dynamics of all 747 proteins identified in uninfected and Borrelia burgdorferi infected Ixodes scapularis nymph tick saliva. Normalized spectral abundance factors (NSAF) values of all I. scapularis nymph tick saliva proteins identified in this study were normalized using the $z$-score statistics and then used to generate heat maps using heatmap2 function in gplots library using $R$ as described in materials and methods. The red color represents high abundance to blue color indicating low abundance. SF5. Secretion dynamics of protein categories identified in uninfected and Borrelia burgdorferi infected Ixodes scapularis nymph tick saliva. Normalized spectral abundance factors (NSAF) values of I. scapularis nymph tick saliva proteins grouped in categories were normalized using the $z$-score statistics and then used to generate heat maps using heatmap2 function in gplots library using $R$ as described in materials and methods. The red color represents high abundance to blue color indicating low abundance. A- immune related, B- glycine rich, C- extracelIular matrix, D- cytoskeletal, E- detoxification/ antioxidant, F- heme/iron binding, G- nucleic acid metabolism, $\mathrm{H}$ - nuclear regulation, I- transcription machinery, J- amino acid metabolism, K- carbohydrate metabolism, L- energy metabolism, $\mathrm{M}$ - protein modification, $\mathrm{N}$ - protein export, $\mathrm{O}$ - protein synthesis, P- proteasome machinery, Q- transporters/receptors, R- signal transduction, and S- tick-specific saliva proteins of unknown function.

SF6. Borrelia burgdorferi $(B b)$ infection modifies protein content on composition of rabbit (host) proteins in Ixodes scapularis nymph saliva. Cumulative normalized spectral abundance factor (NSAF) value, the index for relative protein abundance for all rabbit (host) proteins in saliva of uninfected and $B b$ infected nymph ticks was normalized using the $z$-score statistics and then used to generate heat maps using heatmap2 function in gplots library using $R$ as described in materials and methods. The red to blue transition denotes high to low abundance levels shown in the Zscore range key. The reader is advised that the raw NSAF values that were used to generate the heatmap are provided in S1 Table.

\section{Additional file 2.}

Additional file 3.

\section{Abbreviations}

LD: Lyme disease; Bb: Borrelia burgdorferi; LC-MS/MS: Liquid chromatographytandem mass spectrometry; BSK-H: Barbour-Stoenner-Kelly-H; RT: Room temperature; NSAF: Normalized spectral abundance factors; SDS: Sodium dodecyl sulfate; DTT: Dithiothreitol; IgG: Immunoglobulin G; Serpin: Serine protease inhibitor; TIL: Trypsin inhibitor-like; MP: Metalloprotease; AMP: Antimicrobial peptides; TSP: Tick-specific proteins of unknown function; RNAi: RNA interference; PAR: Protease-activated receptors; NPC: Niemann-Pick type C; ML: MD-2-related lipid-recognition; GRP: Glycine rich proteins; ECM: Extracellular matrix; CS: Cytoskeletal; ROS: Reactive oxygen species; $\mathrm{H}_{2} \mathrm{O}_{2}$ : Hydrogen peroxide; NET: Neutrophil extracellular traps; ATP: Adenine triphosphate; NADH: Nicotinamide adenine dinucleotide hydride; HSP: Heat shock protein; CRT: Calreticulin; IGFBP-rP: Insulin growth factor binding proteins-related proteins; OspC: Outer surface protein C; ELISA: Enzymelinked immunosorbent assay

\section{Acknowledgements}

The authors would like to thank Dr. José M. C. Ribeiro (NIH-NIAID) for providing the VB programs used in protein annotation and Dr. Jon T. Skare for providing the Borrelia burgdorferi B31 strain used in this study.

\section{Authors' contributions}

Conception and design of the work by TKK, LT, AM; acquisition of data by TKK, LT, EB, THK; analysis and interpretation of data by TKK, LT, JD, AM; software provided by JD, JY; original draft by TKK, AM; and revision of draft by TKK, LT, EB, THK, JD, JY, AM. All authors have read and approved the manuscript.

\section{Funding}

This research was supported by National Institutes of Health grants (Al138129 and Al119873) to AM and National Center for Research Resources (5P41RR011823) and National Institute of General Medical Sciences (8P41GM103533) to JRY. The funders had no role in study design, data collection and analysis, decision to publish, or preparation of the manuscript.

\section{Availability of data and materials}

The mass spectrometry proteomics data have been deposited to the ProteomXchange Consortium via the PRIDE partner repository with the dataset identifier PXD023940 and 10.6019/PXD023940. Please note that ST1 includes GenBank accession numbers for tick proteins and Uniprot accession numbers for rabbit proteins.

\section{Ethics approval and consent to participate}

All experiments were done according to the animal use protocol approved by Texas A\&M University Institutional Animal Care and Use Committee (IACUC) (AUP 2017-0068 and 2018-0001) that meets all federal requirements, as defined in the Animal Welfare Act (AWA), the Public Health Service Policy (PHS), and the Humane Care and Use of Laboratory Animals. Rabbits used in this study were commercially purchased through Comparative Medicine Program at Texas A\&M from Harlan Sprague Dawley Inc. (Indianapolis, IN, USA).

\section{Consent for publication}

Not applicable.

\section{Competing interests}

The authors declare that they have no competing interest.

\section{Author details}

'Department of Veterinary Pathobiology, College of Veterinary Medicine, Texas A\&M University, College Station, Texas, United States of America. ${ }^{2}$ Department of Diagnostic Medicine and Veterinary Pathobiology, College of Veterinary Medicine, Kansas State University, Manhattan, Kansas, United States of America. ${ }^{3}$ Laboratory of Bacteriology, National Institute of Allergy and Infectious Diseases, Hamilton, Montana, United States of America. ${ }^{4}$ Department of Molecular Medicine, The Scripps Research Institute, La Jolla, California, United States of America. ${ }^{5}$ Mass Spectrometry Core, Salk Institute for Biological Studies, La Jolla, California, United States of America.

Received: 7 September 2020 Accepted: 8 February 2021

Published online: 04 March 2021

\section{References}

1. Rosenberg R, Lindsey NP, Fischer M, Gregory CJ, Hinckley AF, Mead PS, et al. Vital signs: Trends in reported vectorborne disease cases United States and Territories, 2004-2016. MMWR Morb Mortal Wkly Rep. 2018;67(17):496-501.

2. Harmon JR, Hickling GJ, Scott MC, Jones CJ. Evaluation of 4-poster acaricide applicators to manage tick populations associated with disease risk in a Tennessee retirement community. J Vector Ecol. 2011;36(2):404-10.

3. Garnett JM, Connally NP, Stafford KC, Cartter ML. Evaluation of deertargeted interventions on Lyme disease incidence in Connecticut. Public Health Rep. 2011;126(3):446-54.

4. Wilson ML, Levine JF, Spielman A. Effect of deer reduction on abundance of the deer tick (Ixodes dammini). Yale J Biol Med. 1984;57(4):697-705.

5. Fish D, Childs JE. Community-based prevention of Lyme disease and other tick-borne diseases through topical application of acaricide to white-tailed deer: Background and rationale. Vector Borne Zoonotic Dis. 2009;9(4):357-64.

6. Stafford KC, Denicola AJ, Pound JM, Miller JA, George JE. Topical treatment of white-tailed deer with an acaricide for the control of Ixodes scapularis (Acari: Ixodidae) in a Connecticut Lyme borreliosis hyperendemic community. Vector Borne Zoonotic Dis. 2009;9(4):371-9. 
7. Daniels TJ, Falco RC, Mchugh EE, Vellozzi J, Boccia T, Denicola AJ, et al. Acaricidal treatment of white-tailed deer to control Ixodes scapularis (Acari: Ixodidae) in a New York Lyme disease-endemic community. Vector Borne Zoonotic Dis. 2009:9(4):381-7.

8. Schuijt TJ, Hovius JW, van der Poll T, van Dam AP, Fikrig E. Lyme borreliosis vaccination: The facts, the challenge, the future. Trends Parasitol 2011;27(1): 40-47.

9. Hovius JWR, van Dam AP, Fikrig E. Tick-host-pathogen interactions in Lyme borreliosis. Trends Parasitol 2007;23(9):434-438.

10. Narasimhan S, DePonte K, Marcantonio N, Liang X, Royce TE, Nelson KF, et al. Immunity against Ixodes scapularis salivary proteins expressed within 24 hours of attachment thwarts tick feeding and impairs Borrelia transmission. PLoS One. 2007;2(5):e451.

11. Willadsen P. Anti-tick vaccines. Parasitology. 2004;129(Suppl):S367-87.

12. Nuttall PA. Tick saliva and its role in pathogen transmission. Wien Klin Wochenschr. 2019; https://doi.org/10.1007/s00508-019-1500-y.

13. Nazario S, Das S, de Silva AM, Deponte K, Marcantonio N, Anderson JF, et al. Prevention of Borrelia burgdorferi transmission in guinea pigs by tick immunity. Am J Trop Med Hyg. 1998;58(6):780-5.

14. Craig LE, Norris DE, Sanders ML, Glass GE, Schwartz BS. Acquired resistance and antibody response of raccoons (Procyon lotor) to sequential feedings of Ixodes scapularis (Acari: Ixodidae). Vet Parasitol. 1996;63(3-4):291-301.

15. Schuijt TJ, Narasimhan S, Daffre S, DePonte K, Hovius JWR, van't Veer C, et al. Identification and characterization of Ixodes scapularis antigens that elicit tick immunity using yeast surface display. PLoS One. 2011;6(1):e15926.

16. $\mathrm{Xu} \mathrm{XL}$, Cheng TY, Yang H, Liao ZH. De novo assembly and analysis of midgut transcriptome of Haemaphysalis flava and identification of genes involved in blood digestion, feeding and defending from pathogens. Infect Genet Evol. 2016;38:62-72.

17. Esteves E, Maruyama SR, Kawahara R, Fujita A, Martins LA, Righi AA, et al. Analysis of the salivary gland transcriptome of unfed and partially fed Amblyomma sculptum ticks and descriptive proteome of the saliva. Front Cell Infect Microbiol. 2017;7:476.

18. Xu XL, Cheng TY, Yang H, Yan F, Yang Y. De novo sequencing, assembly and analysis of salivary gland transcriptome of Haemaphysalis flava and identification of sialoprotein genes. Infect Genet Evol. 2015:32:135-42.

19. Lewis LA, Radulović TM, Kim TK, Porter LM, Mulenga A. Identification of $24 \mathrm{~h}$ Ixodes scapularis immunogenic tick saliva proteins. Ticks Tick Borne Dis. 2015;6(3):424-34.

20. Radulović ŽM, Kim TK, Porter LM, Sze SH, Lewis L, Mulenga A. A 24-48 h fed Amblyomma americanum tick saliva immuno-proteome. BMC Genomics. 2014;32:51.

21. Mudenda L, Pierlé SA, Turse JE, Scoles GA, Purvine SO, Nicora CD, et al. Proteomics informed by transcriptomics identifies novel secreted proteins in Dermacentor andersoni saliva. Int J Parasitol. 2014:44(13):1029-37.

22. Tirloni L, Kim TK, Pinto AFM, Yates JR, da Silva VI, Mulenga A. Tick-host range adaptation: Changes in protein profiles in unfed adult Ixodes scapularis and Amblyomma americanum saliva stimulated to feed on different hosts. Front Cell Infect Microbiol. 2017;7:517.

23. Tirloni L, Reck J, Terra RMS, Martins JR, Mulenga A, Sherman NE, et al. Proteomic analysis of cattle tick Rhipicephalus (Boophilus) microplus saliva: A comparison between partially and fully engorged females. PLoS One. 2014;9(4):e94831.

24. Kim TK, Tirloni L, Pinto AFM, Moresco J, Yates JRIII, da Silva Vaz I Jr, Mulenga A. Ixodes scapularis tick saliva proteins sequentially secreted every $24 \mathrm{~h}$ during blood Feeding. PLoS Negl Trop Dis. 2016;10(1):e0004323.

25. Tirloni L, Islam MS, Kim TK, Diedrich JK, Yates JR, Pinto AFM, et al. Saliva from nymph and adult females of Haemaphysalis longicornis: A proteomic study. Parasit Vectors. 2015;8:338.

26. Kim TK, Tirloni L, Pinto AFM, Diedrich JK, Moresco JJ, Yates JR 3rd, da Silva Vaz I Jr, Mulenga A. Time-resolved proteomic profile of Amblyomma americanum tick saliva during feeding. PLoS Negl Trop Dis. 2020;14(2): e0007758.

27. Mansfield KL, Cook C, Ellis RJ, Bell-Sakyi L, Johnson N, Alberdi P, et al. Tickborne pathogens induce differential expression of genes promoting cell survival and host resistance in /xodes ricinus cells. Parasit Vectors. 2017;10(1):81.

28. Martins LA, de Melo Galletti MFB, Ribeiro JM, Fujita A, Costa FB, Labruna MB, et al. The distinct transcriptional response of the midgut of Amblyomma sculptum and Amblyomma aureolatum ticks to Rickettsia rickettsii correlates to their differences in susceptibility to infection. Front Cell Infect Microbiol. 2017;7:129.

29. Villar M, Ayllón N, Kocan KM, Bonzón-Kulichenko E, Alberdi P, Blouin EF, et al. Identification and characterization of Anaplasma phagocytophilum proteins involved in infection of the tick vector, Ixodes scapularis. PLoS One. 2015;10(9):e0137237

30. Villar M, Ayllón N, Alberdi P, Moreno A, Moreno M, Tobes R, et al. Integrated metabolomics, transcriptomics and proteomics identifies metabolic pathways affected by Anaplasma phagocytophilum infection in tick cells. Mol Cell Proteomics. 2015;14(12):3154-72.

31. Antunes S, Couto J, Ferrolho J, Rodrigues F, Nobre J, Santos AS, et al. Rhipicephalus bursa sialotranscriptomic response to blood feeding and Babesia ovis infection: Identification of candidate protective antigens. Front Cell Infect Microbiol. 2018;8:116.

32. Des Vignes F, Piesman J, Heffernan R, Schulze TL, Stafford KCIII, Fish D. Effect of Tick Removal on Transmission of Borrelia burgdorferi and Ehrlichia phagocytophila by Ixodes scapularis Nymphs. J Infect Dis. 2001;183(5):773-8.

33. Cook MJ. Lyme borreliosis: A review of data on transmission time after tick attachment. Int J Gen Med. 2014:8:1-8.

34. Eisen $L$. Pathogen transmission in relation to duration of attachment by |xodes scapularis ticks. Ticks Tick Borne Dis. 2018;9(3):538-42.

35. Broadwater AH, Sonenshine DE, Hynes WL, Ceraul S, De SA. Glass capillary tube feeding: a method for infecting nymphal Ixodes scapularis (Acari: Ixodidae) with the lyme disease spirochete Borrelia burgdorferi. J Med Entomol. 2002:39:285-92.

36. Ribeiro JMC, Zeidner NS, Ledin K, Dolan MC, Mather TN. How much pilocarpine contaminates pilocarpine-induced tick saliva? Med Vet Entomol. 2004;18(1):20-4.

37. Saito Y, Konnai S, Yamada S, et al. Identification and characterization of antimicrobial peptide, defensin, in the taiga tick, Ixodes persulcatus. Insect Mol Biol. 2009;18(4):531-9.

38. Zhu W, Smith JW, Huang C-M. Mass Spectrometry-Based Label-Free Quantitative Proteomics. Biomed Res Int. 2010;2010:6 Article ID 840518. https://doi.org/10.1155/2010/840518.

39. Ankney JA, Muneer A, Chen X. Relative and Absolute Quantitation in Mass Spectrometry-Based Proteomics. Ann Rev Analy Chem. 2018;11(1):49-77.

40. Paoletti AC, Parmely TJ, Tomomori-Sato C, Sato S, Zhu D, Conaway RC, et al. Quantitative proteomic analysis of distinct mammalian Mediator complexes using normalized spectral abundance factors. Proc Natl Acad Sci U S A. 2006:103(50):18928-33.

41. Warnes GR, Bolker B, Bonebakker L, Gentleman R, Huber W, Liaw A, et al. Gplots: Various R programming tools for plotting data. 2016.

42. Rawlings ND. Peptidase specificity from the substrate cleavage collection in the MEROPS database and a tool to measure cleavage site conservation. Biochimie. 2016;122:5-30.

43. Porter LM, Radulović ŽM, Mulenga A. A repertoire of protease inhibitor families in Amblyomma americanum and other tick species: inter-species comparative analyses. Parasit Vectors. 2017;10(1):152.

44. Porter L, Radulović Z, Kim T, Braz GRC, da Silva VI, Mulenga A. Bioinformatic analyses of male and female Amblyomma americanum tick expressed serine protease inhibitors (serpins). Ticks Tick Borne Dis. 2015;6(1):16-30.

45. Rau JC, Beaulieu LM, Huntington JA, Church FC. Serpins in thrombosis, hemostasis and fibrinolysis. J Thromb Haemost. 2007:5(Suppl 1):102-15.

46. Silverman GA, Bird PI, Carrell RW, Church FC, Coughlin PB, Gettins PGW, et al. The serpins are an expanding superfamily of structurally similar but functionally diverse proteins. Evolution, mechanism of inhibition, novel functions, and a revised nomenclature. J Biol Chem. 2001:276(38):33293-6.

47. Olson ST, Gettins PGW. Regulation of proteases by protein inhibitors of the serpin superfamily. Prog Mol Biol Transl Sci. 2011:99:185-240.

48. Patston PA, Gettins PG, Schapira M. The Mechanism by Which Serpins Inhibit Thrombin and Other Serine Proteinases. Ann N Y Acad Sci. 1994;714: 13-20.

49. Mulenga A, Sugino M, Nakajima M, Sugimoto C, Onuma M. Tick-Encoded Serine Proteinase Inhibitors (Serpins); Potential Target Antigens for Tick Vaccine Development. J Vet Med Sci. 2001;63(10):1063-9.

50. Mulenga A, Khumthong R, Chalaire KC. Ixodes scapularis tick serine proteinase inhibitor (serpin) gene family; annotation and transcriptional analysis. BMC Genomics. 2009;10:217.

51. Mulenga A, Khumthong R, Blandon MA. Molecular and expression analysis of a family of the Amblyomma americanum tick Lospins. J Exp Biol. 2007; 20(Pt 18):3188-98.

52. Ibelli AMG, Kim TK, Hill CC, Lewis LA, Bakshi M, Miller S, et al. A blood meal induced Ixodes scapularis tick saliva serpin inhibits trypsin and thrombin, and interferes with platelet aggregation and blood clotting. Int J Parasitol. 2014;44(6):369-79 
53. Kim TK, Tirloni L, Radulovic Z, Lewis L, Bakshi M, Hill C, et al. Conserved Amblyomma americanum tick Serpin19, an inhibitor of blood clotting factors Xa and Xla, trypsin and plasmin, has anti-haemostatic functions. Int J Parasitol. 2015;45(9-10):613-27.

54. Bakshi M, Kim TK, Mulenga A. Disruption of blood meal-responsive serpins prevents Ixodes scapularis from feeding to repletion. Ticks Tick Borne Dis. 2018;9(3):506-18.

55. Kim TK, Radulovic Z, Mulenga A. Target validation of highly conserved Amblyomma americanum tick saliva serine protease inhibitor 19. Ticks Tick Borne Dis. 2016;7(3):405-14.

56. Radulović ŽM, Mulenga A. Heparan sulfate/heparin glycosaminoglycan binding alters inhibitory profile and enhances anticoagulant function of conserved Amblyomma americanum tick saliva serpin 19. Insect Biochem Mol Biol. 2017;80:1-10

57. Chmelar J, Oliveira CJ, Rezacova P, Francischetti IMB, Kovarova Z, Pejler G, et al. A tick salivary protein targets cathepsin $\mathrm{G}$ and chymase and inhibits host inflammation and platelet aggregation. Blood. 2011;117(2):738-44.

58. Rehman AA, Ahsan H, Khan FH. Alpha-2-macroglobulin: A physiological guardian. J Cell Physiol. 2013;228(8):1665-75.

59. Mulenga A, Macaluso KR, Simser JA, Azad AF. The American dog tick, Dermacentor variabilis, encodes a functional histamine release factor homolog. Insect Biochem Mol Biol. 2003;33(9):911-9.

60. Buresova V, Hajdusek O, Franta Z, Sojka D, Kopacek P. IrAM-An a2macroglobulin from the hard tick Ixodes ricinus: Characterization and function in phagocytosis of a potential pathogen Chryseobacterium indologenes. Dev Comp Immunol. 2009;33(4):489-98.

61. Chmelař J, Kotál J, Langhansová H, Kotsyfakis M. Protease inhibitors in tick saliva: The role of serpins and cystatins in tick-host-pathogen interaction. Front Cell Infect Microbiol. 2017;7:216.

62. Yu X, Zhou Y, Cao J, Zhang H, Gong H, Zhou J. Caspase-1 participates in apoptosis of salivary glands in Rhipicephalus haemaphysaloides. Parasit Vectors. 2017;10(1):225

63. Pichu S, Ribeiro JMC, Mather TN, Francischetti IMB. Purification of a serine protease and evidence for a protein C activator from the saliva of the tick, Ixodes scapularis. Toxicon. 2014;77:32-9.

64. Horn M, Nussbaumerová $M$, Šanda M, Kovářová Z, Srba J, Franta Z, et al. Hemoglobin Digestion in Blood-Feeding Ticks: Mapping a Multipeptidase Pathway by Functional Proteomics. Chem Biol. 2009; 16(10):1053-63

65. Mulenga A, Misao O, Sugimoto C. Three serine proteinases from midguts of the hard tick Rhipicephalus appendiculatus; cDNA cloning and preliminary characterization. Exp Appl Acarol. 2003;29(1-2):151-64.

66. Mulenga A, Sugimoto C, Onuma M. Characterization of proteolytic enzymes expressed in the midgut of Haemaphysalis longicornis. Jpn J Vet Res. 1999; 46(4):179-84.

67. Tsuji N, Miyoshi T, Battsetseg B, Matsuo T, Xuan X. Fujisaki K. A cysteine protease is critical for Babesia spp. transmission in Haemaphysalis ticks. PLoS Pathog. 2008;4(5):e1000062.

68. Mulenga A, Erikson K. A snapshot of the Ixodes scapularis degradome. Gene. 2011;482(1-2):78-93.

69. Markland FS, Swenson S. Snake venom metalloproteinases. Toxicon. 2013;62:3-18.

70. Francischetti IMB, Mather TN, Ribeiro JMC. Cloning of a salivary gland metalloprotease and characterization of gelatinase and fibrin(ogen)lytic activities in the saliva of the Lyme disease tick vector Ixodes scapularis. Biochem Biophys Res Commun. 2003;305(4):869-75.

71. Decrem Y, Mariller M, Lahaye K, Blasioli V, Beaufays J, Zouaoui Boudjeltia K, et al. The impact of gene knock-down and vaccination against salivary metalloproteases on blood feeding and egg laying by Ixodes ricinus. Int J Parasitol. 2008;38(5):549-60.

72. Walsh PN, Ahmad SS. Proteases in blood clotting. Essays in Biochem. London: Portland Press Ltd; 2002. p. 95-111.

73. Patel S. A critical review on serine protease: Key immune manipulator and pathology mediator. Allergol Immunopathol. 2017;45(6):579-91.

74. Weidmann H, Heikaus L, Long AT, Naudin C, Schlüter H, Renné T. The plasma contact system, a protease cascade at the nexus of inflammation, coagulation and immunity. Biochim Biophys Acta, Mol Cell Res. 2017; 1864(11 Pt B):2118-27.

75. Bouwens EAM, Stavenuiter F, Mosnier LO. Mechanisms of anticoagulant and cytoprotective actions of the protein C pathway. J Thromb Haemost. 2013; 11(Suppl 1):242-53.
76. Gillespie JP, Kanost MR, Trenczek T. Biological mediators of insect immunity. Annu Rev Entomol. 1997;42:611-43.

77. Cerenius L, Lee BL, Söderhäll K. The proPO-system: pros and cons for its role in invertebrate immunity. Trends Immunol. 2008;29(6):263-71.

78. Chan QW, Melathopoulos AP, Pernal SF, Foster $L$. The innate immune and systemic response in honey bees to a bacterial pathogen, Paenibacillus larvae. BMC Genomics. 2009;10:387.

79. Choo YM, Lee KS, Yoon HJ, et al. Dual function of a bee venom serine protease: prophenoloxidase-activating factor in arthropods and fibrin(ogen)olytic enzyme in mammals. PLoS One. 2010;5(5):e10393.

80. Posma JJN, Posthuma JJ, Spronk HMH. Coagulation and non-coagulation effects of thrombin. J Thromb Haemost. 2016;14(10):1908-16.

81. Fu Q, Cheng J, Gao Y, Zhang Y, Chen X, Xie J. Protease-Activated Receptor 4: A Critical Participator in Inflammatory Response. Inflammation. 2015;38(2): 886-95.

82. Rezaie AR. Protease-activated receptor signalling by coagulation proteases in endothelial cells. Thromb Haemost. 2014;112(5):876-82.

83. Zavašnik-Bergant $T$, Turk B. Cysteine cathepsins in the immune response. Tissue Antigens. 2006;67(5):349-55.

84. Colbert JD, Matthews SP, Miller G, Watts C. Diverse regulatory roles for Iysosomal proteases in the immune response. Eur J Immunol. 2009;39(11): 2955-65.

85. Siqueira-Neto JL, Debnath A, McCall LI, Bernatchez JA, Ndao M, Reed SL, et al. Cysteine proteases in protozoan parasites. PLoS Negl Trop Dis. 2018;12(8): e0006512.

86. Grote A, Caffrey CR, Rebello KM, Smith D, Dalton JP, Lustigman S. Cysteine proteases during larval migration and development of helminths in their final host. PLoS Negl Trop Dis. 2018;12(8):e0005919.

87. Ferreira LG, Andricopulo AD. Targeting cysteine proteases in trypanosomatid disease drug discovery. Pharm Ther. 2017;180:49-61.

88. Pohl PC, Sorgine MH, Leal AT, et al. An extraovarian aspartic protease accumulated in tick oocytes with vitellin-degradation activity. Comp Biochem Physiol B Biochem Mol Biol. 2008;151(4):392-9.

89. Mahmood W, Viberg LT, Fischer K, Walton SF, Holt DC. An Aspartic Protease of the Scabies Mite Sarcoptes scabiei Is Involved in the Digestion of Host Skin and Blood Macromolecules. PLoS Negl Trop Dis. 2013;7(11):e2525.

90. Pathak AK, Helm BA. Proteomic identification and characterization of secreted N-glycosylated NPC2 following cross-linking of the high-affinity receptor for lgE on mast cells. Cell Biol Int. 2010;34(4):353-9.

91. Ao JQ, Ling E, Rao XJ, Yu XQ. A novel ML protein from Manduca sexta may function as a key accessory protein for lipopolysaccharide signaling. Mol Immunol. 2008;45(10):2772-81.

92. Li X, Saha P, Lib J, Blobel G, Pfeffer SR. Clues to the mechanism of cholesterol transfer from the structure of NPC1 middle lumenal domain bound to NPC2. Proc Nat Acad USA. 2016;113(36):10079-84.

93. Davies JP, Levy B, loannou YA. Evidence for a niemann-pick C (NPC) gene family: Identification and characterization of NPC1L1. Genomics. 2000;65(2): 137-45.

94. Vijayaraj P, Sabarirajan J, Nachiappan V. Enhanced phospholipase B activity and alteration of phospholipids and neutral lipids in Saccharomyces cerevisiae exposed to $\mathrm{N}$-nitrosonornicotine. Antonie Van Leeuwenhoek. 2011;99(3):567-77.

95. Mima J, Narita Y, Chiba H, Hayashi R. The multiple site binding of carboxypeptidase $Y$ inhibitor (IC) to the cognate proteinase. Implications for the biological roles of the phosphatidylethanolamine-binding protein. J Biol Chem. 2003;278(32):29792-8.

96. Tang $M$, Dong $Z$, Guo $P$, et al. Functional analysis and characterization of antimicrobial phosphatidylethanolamine-binding protein BmPEBP in the silkworm Bombyx mori. Insect Biochem Mol Biol. 2019;110:1-9.

97. Dougherty MK, Morrison DK. Unlocking the code of 14-3-3. J Cell Sci. 2004; 117(10):1875-84.

98. Liu J, Dyer D, Wang J, Wang S, Du X, Xu B, et al. 3-Oxoacyl-ACP Reductase from Schistosoma japonicum: Integrated In Silico-In Vitro Strategy for Discovering Antischistosomal Lead Compounds. PLoS One. 2013;8(6):e64984

99. Wickramasinghe SR, Inglis KA, Urch JE, Müller S, van Aalten DMF, Fairlamb $\mathrm{AH}$. Kinetic, inhibition and structural studies on 3-oxoacyl-ACP reductase from Plasmodium falciparum, a key enzyme in fatty acid biosynthesis. Biochem J. 2006:393(2):447-57.

100. Crowley JT, Toledo AM, LaRocca TJ, Coleman JL, London E, Benach JL. Lipid Exchange between Borrelia burgdorferi and Host Cells. PLoS Pathog. 2013; 9(1):e1003109. 
101. Toledo A, Monzón JD, Coleman JL, Garcia-Monco JC, Benach JL. Hypercholesterolemia and ApoE deficiency result in severe infection with Lyme disease and relapsing-fever Borrelia. Proc Natl Acad Sci U S A. 2015; 112(17):5491-6.

102. Flower DR, North AC, Sansom CE. The lipocalin protein family: structural and sequence overview. Biochim Biophys Acta. 2000;1482(1-2):9-24.

103. Paesen GC, Adams PL, Harlos K, Nuttall PA, Stuart DI. Tick histamine-binding proteins: isolation, cloning, and three-dimensional structure. Mol Cell. 1999; 3(5):661-71.

104. Paesen GC, Adams PL, Nuttall PA, Stuart DL. Tick histamine-binding proteins: lipocalins with a second binding cavity. Biochim Biophys Acta. 2000;1482(12):92-101.

105. Kemp D, Bourne A. Boophilus microplus: The effect of histamine on the attachment of cattle-tick larvae-studies in vivo and in vitro. Parasitology. 1980;80(3):487-96.

106. Nakano M, Oda K, Mukaihara T. Ralstonia solanacearum novel E3 ubiquitin ligase (NEL) effectors RipAW and RipAR suppress pattern-triggered immunity in plants. Microbiology. 2017;163(7):992-1002.

107. Ünal CM, Steinert M. Microbial peptidyl-prolyl cis/trans isomerases (PPlases): virulence factors and potential alternative drug targets. Microbiol Mol Biol Rev. 2014;78(3):544-71.

108. Hofmann A, Osman A, Leow CY, Driguez P, McManus DP, Jones MK. Parasite annexins - New molecules with potential for drug and vaccine development. Hoboken: BioEssays; 2010. p. 967-76.

109. Martin M, Leffler J, Blom AM. Annexin A2 and A5 serve as new ligands for C1q on apoptotic cells. J Biol Chem. 2012;287(40):33733-44.

110. Renner B, Tong HH, Laskowski J, et al. Annexin A2 Enhances Complement Activation by Inhibiting Factor H. J Immunol. 2016;196(3):1355-65.

111. Zhi H, Xie J, Skare JT. The Classical Complement Pathway Is Required to Control Borrelia burgdorferi Levels During Experimental Infection. Front Immunol. 2018;9:959.

112. de Trez C, Ware CF. The TNF receptor and Ig superfamily members form an integrated signaling circuit controlling dendritic cell homeostasis. Cytokine Growth Factor Rev. 2008;19(3-4):277-84.

113. DeBoer J, Madson CJ, Belshan M. Cyclophilin B enhances HIV-1 infection. Virology. 2016:489:282-91.

114. Zhao K, Li J, He W, Song D, Zhang X, Zhang D, et al. Cyclophilin B facilitates the replication of Orf virus. Virol J. 2017;14(1):114

115. Dawar FU, Tu J, Khattak MNK, Mei J, Lin L. Cyclophilin a: A key factor in virus replication and potential target for anti-viral therapy. Curr Issues Mol Biol. 2017;21:1-20.

116. Lesch C, Goto A, Lindgren M, Bidla G, Dushay MS, Theopold U. A role for Hemolectin in coagulation and immunity in Drosophila melanogaster. Dev Comp Immunol. 2007;31(12):1255-63.

117. Goto A, Kumagai T, Kumagai C, Hirose J, Narita H, Mori H, et al. A Drosophila haemocyte-specific protein, hemolectin, similar to human von Willebrand factor. Biochem J. 2001;359(1):99-108.

118. Akkaya M, Akkaya B, Kim AS, et al. Toll-like receptor 9 antagonizes antibody affinity maturation. Nat Immunol. 2018;19(3):255-66.

119. Ashley SN, Somanathan S, Giles AR, Wilson JM. TLR9 signaling mediates adaptive immunity following systemic AAV gene therapy. Cell Immunol. 2019;346:103997.

120. Hollmann T, Kim TK, Tirloni L, Radulović ŽM, Pinto AFM, Diedrich JK, et al. Identification and characterization of proteins in the Amblyomma americanum tick cement cone. Int J Parasitol. 2018;48(3-4):211-24.

121. Raibaud S, Schwarz-Linek U, Kim JH, et al. Borrelia burgdorferi binds fibronectin through a tandem beta-zipper, a common mechanism of fibronectin binding in staphylococci, streptococci, and spirochetes. J Biol Chem. 2005;280(19):18803-9.

122. Niddam AF, Ebady R, Bansal A, Koehler A, Hinz B, Moriarty TJ. Plasma fibronectin stabilizes Borrelia burgdorferi-endothelial interactions under vascular shear stress by a catch-bond mechanism. Proc Natl Acad Sci U S A. 2017;114(17):E3490-8.

123. Caine JA, Coburn J. A short-term Borrelia burgdorferi infection model identifies tissue tropisms and bloodstream survival conferred by adhesion proteins. Infect Immun. 2015;83(8):3184-94.

124. Itoh T, Hibi T, Fujii Y, Sugimoto I, Fujiwara A, Suzuki F, et al. Cooperative degradation of chitin by extracellular and cell surface-expressed chitinases from Paenibacillus sp. strain FPU7. Appl Environ Microbiol. 2013;79(23):7482-90.

125. Arakane Y, Muthukrishnan S. Insect chitinase and chitinase-like proteins. Cell Mol Life Sci. 2010;67:201-16.
126. Kim TK, Curran J, Mulenga A. Dual silencing of long and short Amblyomma Americanum acidic chitinase forms weakens the tick cement cone stability. J Exp Biol. 2014;217(19):3493-503.

127. Almeida F, Sardinha-Silva A, da Silva TA, Pessoni AM, Pinzan CF, AlegreMaller ACP, et al. Toxoplasma gondii chitinase induces macrophage activation. PLoS One. 2015;10(12):e0144507.

128. Kristó I, Bajusz I, Bajusz C, Borkúti P, Vilmos P. Actin, actin-binding proteins, and actin-related proteins in the nucleus. Histochem Cell Biol. 2016;145(4): 373-88.

129. Naj X, Hoffmann AK, Himmel M, Linder S. The formins FMNL1 and mDia1 regulate coiling phagocytosis of Borrelia burgdorferi by primary human macrophages. Infect Immun. 2013;81(5):1683-95.

130. Wolgemuth CW, Charon NW, Goldstein SF, Goldstein RE. The flagellar cytoskeleton of the spirochetes. J Mol Microbiol Biotechnol. 2006;11(3-5): 221-7.

131. Hyde JA, Shaw DK, Smith R, Trzeciakowski JP, Skare JT. The BosR regulatory protein of Borrelia burgdorferi interfaces with the RpoS regulatory pathway and modulates both the oxidative stress response and pathogenic properties of the Lyme disease spirochete. Mol Microbiol. 2009:74(6):1344-55.

132. Showman AC, Aranjuez G, Adams PP, Jewett MW. Gene bb0318 is critical for the oxidative stress response and infectivity of Borrelia burgdorferi. Infect Immun. 2016;84(11):3141-51.

133. Ozyigit II, Filiz E, Vatansever R, Kurtoglu KY, Koc I, Öztürk MX, et al. Identification and comparative analysis of $\mathrm{H}_{2} \mathrm{O} 2$-scavenging enzymes (ascorbate peroxidase and glutathione peroxidase) in selected plants employing bioinformatics approaches. Front Plant Sci. 2016;7:301.

134. Rundlöf A-K, Arnér ESJ. Regulation of the mammalian selenoprotein thioredoxin reductase 1 in relation to cellular phenotype, growth, and signaling events. Antioxid Redox Signal. 2004;6(1):41-52.

135. Hayes JD, Flanagan JU, Jowsey IR. Glutathione transferases. Annu Rev Pharmacol Toxicol. 2005;45:51-88.

136. McCord JM, Fridovich I. Superoxide dismutase. An enzymic function for erythrocuprein (hemocuprein). J Biol Chem. 1969;244:6049-55.

137. Fraser CM, Casjens S, Huang WM, Sutton GG, Clayton R, Lathigra R, et al. Genomic sequence of a Lyme disease spirochaete, Borrelia burgdorferi. Nature. 1997:390(6660):580-6.

138. Boylan JA, Posey JE, Gherardini FC. Borrelia oxidative stress response regulator, BosR: a distinctive $\mathrm{Zn}$-dependent transcriptional activator. Proc Natl Acad Sci USA. 2003;100(20):11684-9.

139. Dulebohn DP, Richards CL, Su H, Lawrence KA, Gherardini FC. Weak Organic Acids Decrease Borrelia burgdorferi Cytoplasmic pH, Eliciting an Acid Stress Response and Impacting RpoN- and RpoS-Dependent Gene Expression. Front Microbiol. 2017;8:1734

140. Murgia R, Cinco M. Induction of cystic forms by different stress conditions in Borrelia burgdorferi. APMIS. 2004;112(1):57-62.

141. Seshu J, Boylan JA, Hyde JA, Swingle KL, Gherardini FC, Skare JT. A conservative amino acid change alters the function of BosR, the redox regulator of Borrelia burgdorferi. Mol Microbiol. 2004;54(5):1352-63.

142. Hyde JA, Shaw DK, Smith R 3rd, Trzeciakowski JP, Skare JT. Characterization of a conditional bosR mutant in Borrelia burgdorferi. Infect Immun. 2010; 78(1):265-74.

143. Boylan JA, Lawrence KA, Downey JS, Gherardini FC. Borrelia burgdorferi membranes are the primary targets of reactive oxygen species. Mol Microbiol. 2008;68(3):786-99.

144. Ratledge C, Dover LG. Iron metabolism in pathogenic bacteria. Annu Rev Microbiol. 2000;54:881-941.

145. Sheldon JR, Laakso HA, Heinrichs DE. Iron Acquisition Strategies of Bacterial Pathogens. Microbiol Spectrum. 2016;4(2):10.1128.

146. Posey JE, Gherardini FC. Lack of a role for iron in the Lyme disease pathogen. Science. 2000;288(5471):1651-3.

147. Sambri V, Cevenini R, la Placa M. Susceptibility of iron-loaded Borrelia burgdorferi to killing by hydrogen peroxide and human polymorphonuclear leucocytes. FEMS Microbiol Lett. 1991;65(1):67-71.

148. Arosio P, Elia L, Poli M. Ferritin, cellular iron storage and regulation. IUBMB Life. 2017;69(6):414-22.

149. Zimmermann H, Zebisch M, Sträter N. Cellular function and molecular structure of ectonucleotidases. Purinergic Signal. 2012;8(3):437-502.

150. Bianchi V, Spychala J. Mammalian 5'-nucleotidases. J Biol Chem. 2003; 278(47):46195-8.

151. Péterfi O, Boda F, Szabó Z, Ferencz E, Bába L. Hypotensive Snake Venom Components-A Mini-Review. Molecules. 2019;24:15. 
152. Hart ML, Köhler D, Eckle T, Kloor D, Stahl GL, Eltzschig HK. Direct treatment of mouse or human blood with soluble 5'-nucleotidase inhibits platelet aggregation. Arterioscler Thromb Vasc Biol. 2008;28(8):1477-83.

153. Johnson GJ, Schwartz BS, Leis LA. In vivo platelet retention in human bleeding-time wounds. I. Normal subjects and patients with platelet dysfunction. J Lab Clin Med. 1979;94(4):563.

154. Schwartz BS, Leis LA, Johnson GJ. In vivo platelet retention in human bleeding-time wounds. II. Effect of aspirin ingestion. J Lab Clin Med. 1979; 94(4):574-84.

155. Hammond CM, Strømme CB, Huang H, Patel DJ, Groth A. Histone chaperone networks shaping chromatin function. Nat Rev Mol Cell Biol. 2017;18(3):141-58.

156. Nakazawa D, Kumar SV, Marschner J, Desai J, Holderied A, Rath L, et al. Histones and Neutrophil Extracellular Traps Enhance Tubular Necrosis and Remote Organ Injury in Ischemic AKI. J Am Soc Nephrol. 2017: 28(6):1753-68.

157. Hoeksema M, van Eijk M, Haagsman HP, Hartshorn KL. Histones as mediators of host defense, inflammation and thrombosis. Future Microbiol. 2016;11(3):441-53.

158. Menten-Dedoyart C, Faccinetto C, Golovchenko M, Dupiereux I, van Lerberghe P-B, Dubois S, et al. Neutrophil extracellular traps entrap and kill Borrelia burgdorferi sensu stricto spirochetes and are not affected by Ixodes ricinus tick saliva. J Immunol. 2012;189(11):5393-401.

159. Li L, Zhang Q, Yang H, Zou Q, Lai C, Jiang F, et al. Fumarylacetoacetate Hydrolase Knock-out Rabbit Model for Hereditary Tyrosinemia Type 1. J Biol Chem. 2017;292(11):4755-63.

160. Varughese KI, Skinner MM, Whiteley JM, Matthews DA, Xuong NH. Crystal structure of rat liver dihydropteridine reductase. Proc Natl Acad Sci U S A. 1992;89(13):6080-4.

161. Ponzone A, Guardamagna O, Ferraris S, Bracco G, Niederwieser A, Cotton RG. Two mutations of dihydropteridine reductase deficiency. Arch Dis Child. 1988;63(2):154-7.

162. Lowe PN, Rowe AF. Aspartate: 2-oxoglutarate aminotransferase from trichomonas vaginalis. Identity of aspartate aminotransferase and aromatic amino acid aminotransferase. Biochem J. 1985;232(3):689-95.

163. Grant GA. D-3-Phosphoglycerate Dehydrogenase. Front Mol Biosci. 2018; 5:110.

164. Pappas CJ, Iyer R, Petzke MM, Caimano MJ, Radolf JD, Schwartz I. Borrelia burgdorferi requires glycerol for maximum fitness during the tick phase of the enzootic cycle. PLoS Pathog. 2011;7(7):e1002102.

165. Hoon-Hanks LL, Morton EA, Lybecker MC, Battisti JM, Samuels DS, Drecktrah D. Borrelia burgdorferi malQ mutants utilize disaccharides and traverse the enzootic cycle. FEMS Immunol Med Microbiol. 2012;66(2):157-65.

166. Corona A, Schwartz I. Borrelia burgdorferi: Carbon Metabolism and the TickMammal Enzootic Cycle. Microbiol Spectr. 2015;3:3.

167. Oosting M, Kerstholt M, Ter Horst R, et al. Functional and Genomic Architecture of Borrelia burgdorferi-Induced Cytokine Responses in Humans. Cell Host Microbe. 2016;20(6):822-33.

168. Stettner Al, Segrè D. The cost of efficiency in energy metabolism. Proc Natl Acad Sci USA. 2013;110(24):9629-30.

169. Lenzen S. A fresh view of glycolysis and glucokinase regulation: history and current status. J Biol Chem. 2014;289(18):12189-94.

170. Benešová E, Lipovová P, Krejzová J, Koval'ová T, Buchtová P, Spiwok V, et al. Alpha-L-fucosidase isoenzyme iso2 from Paenibacillus thiaminolyticus. BMC Biotechnol. 2015;15:36

171. Melkonian EA, Asuka E, Schury MP. Physiology, Gluconeogenesis. In: StatPearls. Treasure Island: StatPearls Publishing; 2020.

172. Troxell B, Zhang JJ, Bourret TJ, Zeng MY, Blum J, Gherardini F, Hassan HM, Yang XF. Pyruvate protects pathogenic spirochetes from $\mathrm{H} 2 \mathrm{O} 2$ killing. PLoS One. 2014:9:e84625.

173. Israelsen WJ, Vander Heiden MG. Pyruvate kinase: Function, regulation and role in cancer. Semin Cell Dev Biol. 2015:43:43-51.

174. Gómez-Arreaza A, Acosta H, Quiñones W, Concepción JL, Michels PAM, Avilán L. Extracellular functions of glycolytic enzymes of parasites: unpredicted use of ancient proteins. Mol Biochem Parasitol. 2014;193(2): 75-81.

175. de Maio A, Vazquez D. Extracellular heat shock proteins: a new location, a new function. Shock. 2013:40(4):239-46.

176. Carreiro MM, Laux DC, Nelson DR. Characterization of the heat shock response and identification of heat shock protein antigens of Borrelia burgdorferi. Infect Immun. 1990;58(7):2186-91.
177. Cluss RG, Goel AS, Rehm HL, Schoenecker JG, Boothby JT. Coordinate synthesis and turnover of heat shock proteins in Borrelia burgdorferi: degradation of DnaK during recovery from heat shock. Infect Immun. 1996; 64(5):1736-43.

178. Schmitt E, Gehrmann M, Brunet M, Multhoff G, Garrido C. Intracellular and extracellular functions of heat shock proteins: repercussions in cancer therapy. J Leukoc Biol. 2007;81:15-27.

179. Busby AT, Ayllon N, Kocan KM, Blouin EF, de la Fuente G, Galindo RC, et al. Expression of heat shock proteins and subolesin affects stress responses, Anaplasma phagocytophilum infection and questing behaviour in the tick, Ixodes scapularis. Med Vet Entomol. 2012;26(1):92-102.

180. Contreras M, Alberdi P, Mateos-Hernandez L, Fernandez de Mera IG, GarciaPerez AL, Vancova M, et al. Anaplasma phagocytophilum MSP4 and HSP70 Proteins Are Involved in Interactions with Host Cells during Pathogen Infection. Front Cell Infect Microbiol. 2017:7:307.

181. Vichido R, Falcon A, Ramos JA, Alvarez A, Figueroa JV, Norimine J, et al. Expression analysis of heat shock protein 20 and rhoptry-associated protein 1 a in sexual stages and kinetes of Babesia bigemina. Ann N Y Acad Sci. 2008:1149:136-40

182. Vora A, Taank V, Dutta SM, Anderson JF, Fish D, Sonenshine DE, et al. Ticks elicit variable fibrinogenolytic activities upon feeding on hosts with different immune backgrounds. Sci Rep. 2017;7:44593.

183. Surtees R, Dowall SD, Shaw A, Armstrong S, Hewson R, Carroll MW, et al. Heat Shock Protein 70 Family Members Interact with Crimean-Congo Hemorrhagic Fever Virus and Hazara Virus Nucleocapsid Proteins and Perform a Functional Role in the Nairovirus Replication Cycle. J Virol. 2016; 90(20):9305-16.

184. Varricchio L, Falchi M, Dall'Ora M, de Benedittis C, Ruggeri A, Uversky VN, et al. Calreticulin: Challenges Posed by the Intrinsically Disordered Nature of Calreticulin to the Study of Its Function. Front Cell Dev Biol. 2017;5:96.

185. Alarcon-Chaidez F, Ryan R, Wikel S, Dardick K, Lawler C, Foppa IM, et al. Confirmation of tick bite by detection of antibody to /xodes calreticulin salivary protein. Clin Vaccine Immunol. 2006;13(11):1217-22.

186. Sanders ML, Jaworski DC, Sanchez JL, DeFraites RF, Glass GE, Scott AL, et al. Antibody to a cDNA-derived calreticulin protein from Amblyomma americanum as a biomarker of tick exposure in humans. Am J Trop Med Hyg. 1998;59(2):279-85.

187. Sanders ML, Glass GE, Nadelman RB, Wormser GP, Scott AL, Raha S, et al. Antibody levels to recombinant tick calreticulin increase in humans after exposure to Ixodes scapularis (Say) and are correlated with tick engorgement indices. Am J Epidemiol. 1999;149(8):777-84

188. Antunes S, Couto J, Ferrolho J, Sanches GS, Merino Charrez JO, De la Cruz Hernandez N, Mazuz M, Villar M, Shkap V, de la Fuente J, Domingos A. Transcriptome and Proteome Response of Rhipicephalus annulatus Tick Vector to Babesia bigemina Infection. Front Physiol. 2019;10:318.

189. Kim TK, Ibelli AMG, Mulenga A. Amblyomma americanum tick calreticulin binds C1q but does not inhibit activation of the classical complement cascade. Ticks Tick Borne Dis. 2015;6(1):91-101.

190. Hwa V, Oh Y, Rosenfeld RG. The insulin-like growth factor-binding protein (IGFBP) superfamily. Endocr Rev. 1999;20(6):761-87.

191. Radulovic ZM, Porter LM, Kim TK, Bakshi M, Mulenga A. Amblyomma americanum tick saliva insulin-like growth factor binding protein-related protein 1 binds insulin but not insulin-like growth factors. Insect Mol Biol. 2015;24:5

192. Bakshi M, Kim TK, Porter L, Mwangi W, Mulenga A. Amblyomma americanum ticks utilizes countervailing pro and anti-inflammatory proteins to evade host defense. PLoS Pathog. 2019;15(11):e1008128.

193. Mulenga A, Khumthong R. Silencing of three Amblyomma americanum (L.) insulin-like growth factor binding protein-related proteins prevents ticks from feeding to repletion. J Exp Biol. 2010;213(Pt 7):1153-61.

194. Mulenga A, Blandon M, Khumthong R. The molecular basis of the Amblyomma americanum tick attachment phase. Exp Appl Acarol. 2007:41:267-87.

195. Mulenga A, Kim TK, Ibelli AMG. Deorphanization and target validation of cross-tick species conserved novel Amblyomma americanum tick saliva protein. Int J Parasitol. 2013;43(6):439-51.

196. Bierwagen P, Szpotkowski K, Jaskolski M, Urbanowicz A. Borrelia outer surface protein $C$ is capable of human fibrinogen binding. FEBS J. 2019; 286(12):2415-28 https://doi.org/10.1111/febs.14810.

197. Pal U, Yang X, Chen M, et al. OspC facilitates Borrelia burgdorferi invasion of Ixodes scapularis salivary glands. J Clin Invest. 2004;113(2):220-30 https://doi. org/10.1172/JCl19894 
198. Zhou W, Woodson M, Neupane B, Bai F, Sherman MB, Choi KH, Neelakanta $\mathrm{G}$, Sultana $\mathrm{H}$. Exosomes serve as novel modes of tick-borne flavivirus transmission from arthropod to human cells and facilitates dissemination of viral RNA and proteins to the vertebrate neuronal cells. PLoS Pathog. 2018; 14:e1006764.

199. Zhang YN, Vernooij F, Ibrahim I, Ooi S, Gijsberts CM, Schoneveld AH, Sen KW, den Ruijter HM, Timmers L, Richards AM, Jong CT, Mazlan I, Wang JW, Lam CS, de Kleijn DP. Extracellular Vesicle Proteins Associated with Systemic Vascular Events Correlate with Heart Failure: An Observational Study in a Dyspnoea Cohort. PLoS One. 2016;11:e0148073.

200. Vargas A, Roux-Dalvai F, Droit A, Lavoie JP. Neutrophil-Derived Exosomes: A New Mechanism Contributing to Airway Smooth Muscle Remodeling. Am J Respir Cell Mol Biol. 2016;55:450-61.

201. Cwiklinski K, de la Torre-Escudero E, Trelis M, Bernal D, Dufresne PJ, Brennan GP, O'Neill S, Tort J, Paterson S, Marcilla A, Dalton JP, Robinson MW. The Extracellular Vesicles of the Helminth Pathogen, Fasciola hepatica: Biogenesis Pathways and Cargo Molecules Involved in Parasite Pathogenesis. Mol Cell Proteomics. 2015;14:3258-73.

202. Marcilla A, Trelis M, Cortes A, Sotillo J, Cantalapiedra F, Minguez MT, Valero ML, Sanchez del Pino MM, Munoz-Antoli C, Toledo R, Bernal D. Extracellular vesicles from parasitic helminths contain specific excretory/secretory proteins and are internalized in intestinal host cells. PLoS One. 2012;7: e45974.

203. Harischandra H, Yuan W, Loghry HJ, Zamanian M, Kimber MJ. Profiling extracellular vesicle release by the filarial nematode Brugia malayi reveals sex-specific differences in cargo and a sensitivity to ivermectin. PLoS Negl Trop Dis. 2018;12:e0006438.

204. Labandeira-Rey M, Seshu J, Skare JT. The absence of linear plasmid 25 or 281 of Borrelia burgdorferi dramatically alters the kinetics of experimental infection via distinct mechanisms. Infect Immun. 2003;71:4608-13.

205. Elias AF, Stewart PE, Grimm D, Caimano MJ, Eggers CH, Tilly K, Bono JL, Akins DR, Radolf JD, Schwan TG, Rosa P. Clonal polymorphism of Borrelia burgdorferi strain B31 Ml: 2002. implications for mutagenesis in an infectious strain background. Infect Immun. 2002;70(4):2139-50 https://doi org/10.1128/iai.70.4.2139-2150.

206. Johnson BJ, Happ CM, Mayer LW, Piesman J. Detection of Borrelia burgdorferi in ticks by species-specific amplification of the flagellin gene. Am J Trop Med Hyg. 1992;47:730-41.

207. McDonald WH, Tabb DL, Sadygov RG, MacCoss MJ, Venable J, Graumann J, et al. MS1, MS2, and SQT-three unified, compact, and easily parsed file formats for the storage of shotgun proteomic spectra and identifications. Rapid Commun Mass Spectrom. 2004;18(18):2162-8.

208. Xu T, Park SK, Venable JD, Wohlschlegel JA, Diedrich JK, Cociorva D, et al. ProLUCID: An improved SEQUEST-like algorithm with enhanced sensitivity and specificity. J Proteome. 2015;129:16-24.

209. Huang Y, Niu B, Gao Y, Fu L, Li W. CD-HIT Suite: a web server for clustering and comparing biological sequences. Bioinformatics. 2010;26(5):680-2.

210. Apweiler R, Bairoch A, Wu CH, et al. UniProt: the Universal Protein knowledgebase. Nucleic Acids Res. 2004;32(Database issue):D115-9.

211. Waterhouse A, Bertoni M, Bienert S, et al. SWISS-MODEL: homology modelling of protein structures and complexes. Nucleic Acids Res. 2018; 46(W1):W296-303.

212. Karim S, Singh P, Ribeiro JMC. A deep insight into the sialotranscriptome of the gulf coast tick, Amblyomma maculatum. PLoS One. 2011;6(12):e28525.

\section{Publisher's Note}

Springer Nature remains neutral with regard to jurisdictional claims in published maps and institutional affiliations.

Ready to submit your research? Choose BMC and benefit from:
- fast, convenient online submission
- thorough peer review by experienced researchers in your field
- rapid publication on acceptance
- support for research data, including large and complex data types
- gold Open Access which fosters wider collaboration and increased citations
- maximum visibility for your research: over 100M website views per year
At BMC, research is always in progress.
Learn more biomedcentral.com/submissions

